Portland State University

PDXScholar

Summer 8-9-2016

\title{
Dietary and Physical Activity Acculturation and Weight Status in Chinese College Students
}

Yanni Zhang

Portland State University

Follow this and additional works at: https://pdxscholar.library.pdx.edu/open_access_etds

Part of the Community Health Commons

Let us know how access to this document benefits you.

\section{Recommended Citation}

Zhang, Yanni, "Dietary and Physical Activity Acculturation and Weight Status in Chinese College Students" (2016). Dissertations and Theses. Paper 3121.

https://doi.org/10.15760/etd.3117

This Thesis is brought to you for free and open access. It has been accepted for inclusion in Dissertations and Theses by an authorized administrator of PDXScholar. Please contact us if we can make this document more accessible: pdxscholar@pdx.edu. 


\title{
Dietary and Physical Activity Acculturation and Weight Status \\ in Chinese College Students
}

\section{by}

\section{Yanni Zhang}

A thesis submitted in partial fulfillment of the requirements for the degree of

\author{
Master of Science \\ in \\ Health Studies
}

Thesis Committee:

Gary R. Brodowicz, Chair

Bernie Lau

Claire Wheeler

Portland State University

2016 
C 2016 Yanni Zhang 


\begin{abstract}
This cross-sectional study examined the relationships between length of residence in the United States (U.S.) and dietary and physical activity acculturation, and the relationships between dietary and physical activity acculturation and weight status in 55 Chinese college students. Length of residence in the U.S. was positively associated with larger portion size, greater amount of physical activity, and change in BMI in male participants. Adoption of a Western diet was associated with weight gain. Portion size change was positively associated with BMI change. Lunch size change was positively correlated with BMI change in males while negatively correlated with BMI change in females. And dinner size change was positively correlated with BMI change in males. This study suggests that dietary acculturation is positively associated with weight gain in Chinese college students. Future interventions focusing on multi-dimensional aspects of dietary behavior change - especially portion size and meal size changes - while emphasizing the importance of changes in physical activity are needed. Such interventions may help maintain healthy weight status and prevent individuals in this population from becoming overweight or obese.
\end{abstract}




\section{Acknowledgements}

I extend my thanks to my academic advisor, Dr. Gary R. Brodowicz and my committee members, Dr. Bernie Lau and Dr. Claire Wheeler, for their careful and thoughtful assistance throughout the process of my thesis project. I would like to thank

the Office of International Affairs, Chinese Student Scholar Association and College of Community Health at Portland State University for assistance in recruitment of subjects for this project. In addition, I want to thank all students for their participation and those who helped me reach the goals that I set for this study. 


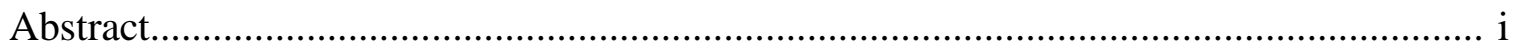

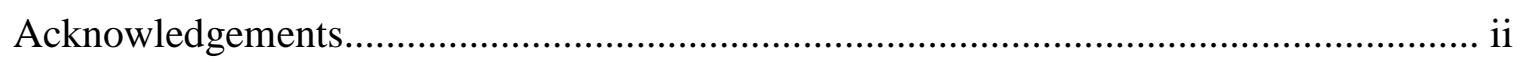

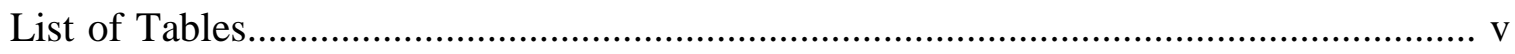

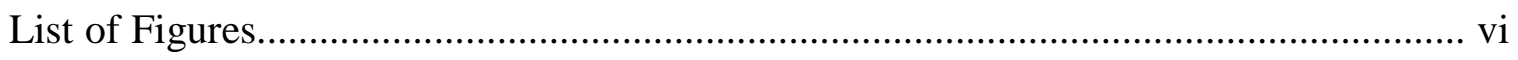

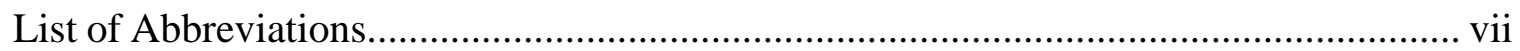

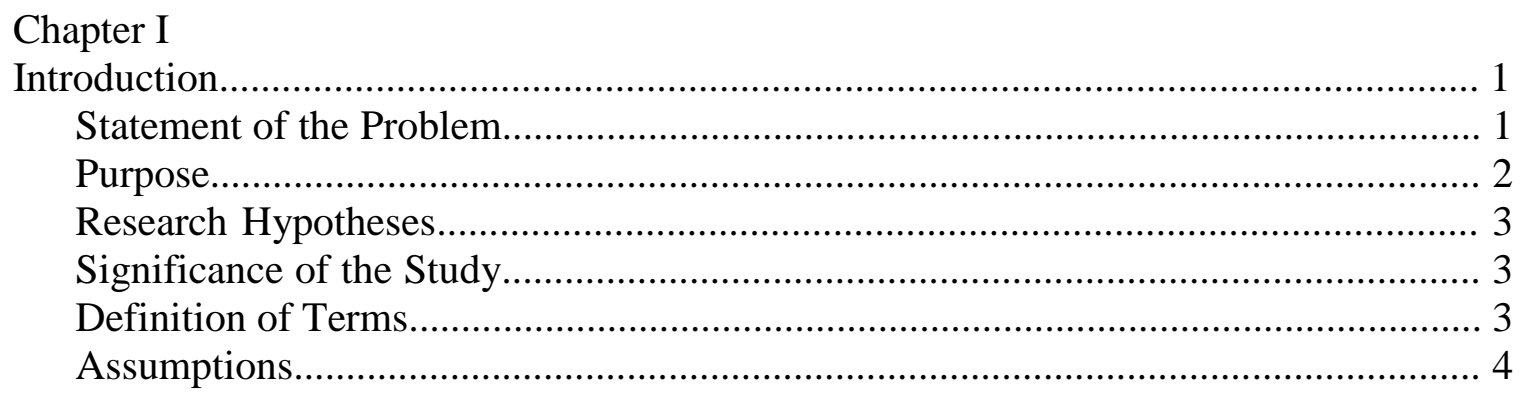

Chapter II

Review of Literature........................................................................................... 5

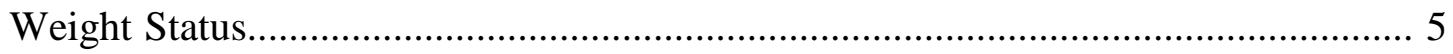

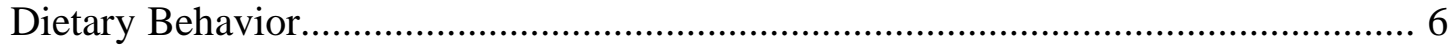

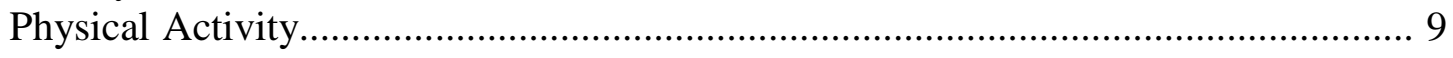

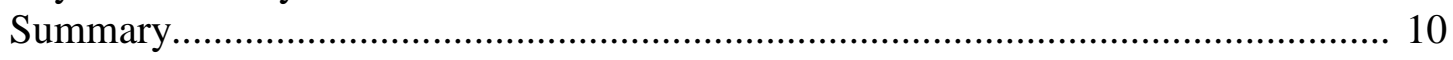

Chapter III

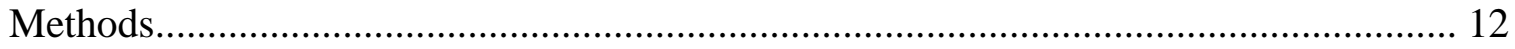

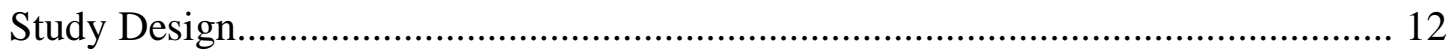

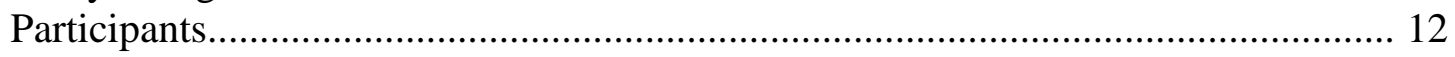

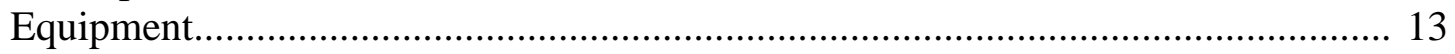

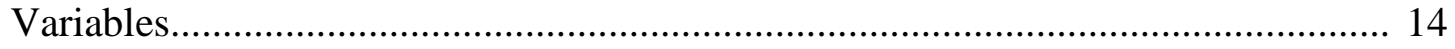

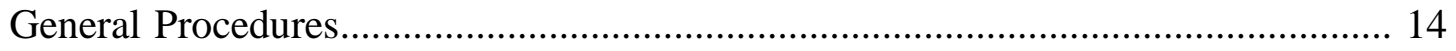

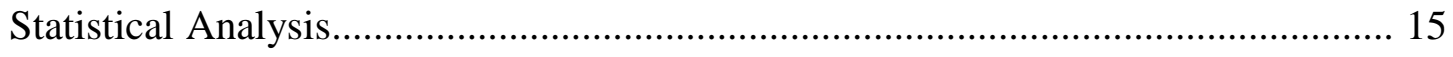

Chapter IV

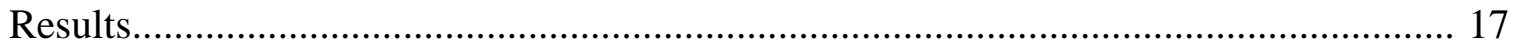

Socio-demographic and Anthropometric Characteristics..................................... 17

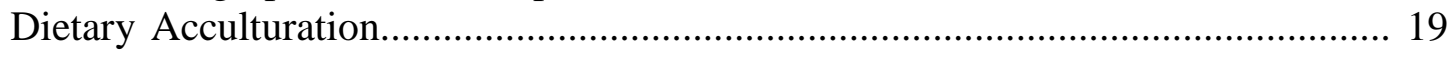

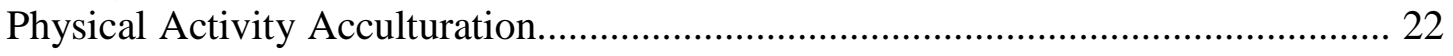

Gender Difference in Physical Activity Acculturation......................................... 23 
Length of Residence and Dietary/Physical Activity Acculturation......................... 23

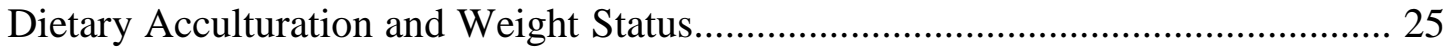

Physical Activity Acculturation and Weight Status................................................ 26

\section{Chapter V}

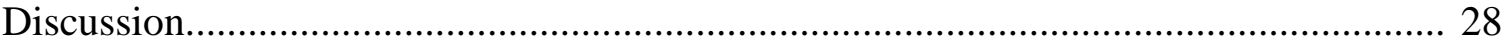

Length of Residence and Dietary/Physical Activity Acculturation.......................... 28

Length of Residence and Weight Status................................................................ 31

Dietary/Physical Activity Acculturation and Weight Status................................... 33

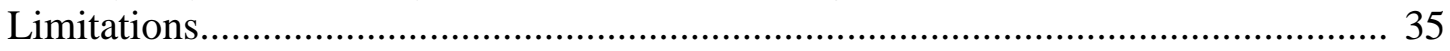

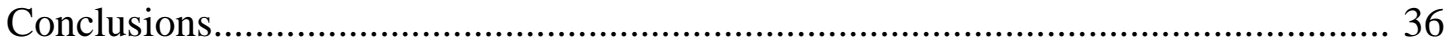

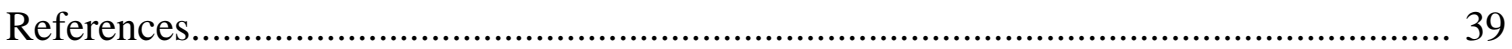

Appendices

A. Dietary and Physical Activity Acculturation Survey......................................... 45

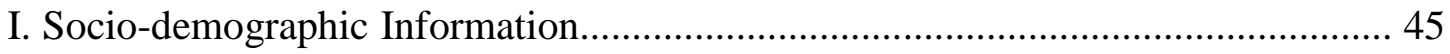

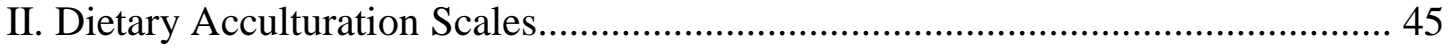

III. International Physical Activity Questionnaire................................................. 46

IV. Self-reported Changes in Diet, Physical Activity and Weight Status Questions... 47

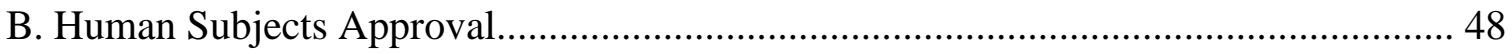




\section{List of Tables}

Table 1. Socio-demographic and anthropometric characteristics................................. 18

Table 2. Length of residence and dietary and PA acculturation.................................. 24

Table 3. Correlation between length of residence and portion size/total PA.................... 25

Table 4. Chinese/Western dietary acculturation and weight status.............................. 25

Table 5. Correlation between dietary acculturation indicators and weight status............ 26

Table 6. Correlation between PA acculturation indicators and weight status.................. 27 


\section{List of Figures}

Figure 1. Percentages of reported changes of Chinese (a) and Western (b) items in dietary acculturation scales............................................................................... 20

Figure 2. Percentages of reported changes of other dietary items................................. 21

Figure 3. Percentages of reported changes of PA accessibility and time................. 22

Figure 4. Changes of time spent on running, bicycling, stair-climbing, walking and

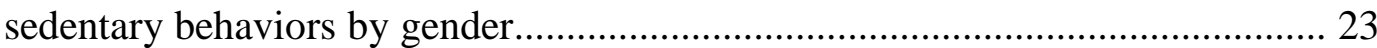




\section{List of Abbreviations}

AHIMSA = Acculturation, Habits, and Interests Multicultural Scale for
BMI = Body Mass Index
CVD = Cardiovascular Disease
IPAQ = International Physical Activity Questionnaire
IPAQ-SF = International Physical Activity Questionnaire-Short Form
LOR = Length of Residence
MET = Metabolic Equivalent
PA = Physical activity
WC = Waist Circumference
WHO = World Health Organization 


\section{Chapter I}

\section{Introduction}

\section{Statement of the Problem}

In the United States (U.S.), the Asian population is one of the fastest growing immigrant populations (Oster \& Yung, 2010), and the Chinese population as the largest sub-group of the Asian population (Rosenmoller, Gasevic, Seidell, \& Lear, 2011; Satia et al., 2001) is the third largest immigrant group with more than 2 million people residing in the U.S. and represents 5\% of the overall immigrant population in 2013 (Hooper \& Batalova, 2015). Compared to people living in the U.S., Chinese people have lower rates of some chronic diseases, such as metabolic disorders, cardiovascular diseases and certain cancers (Lv \& Cason, 2004; Satia et al., 2001). With the "healthy immigrant effect," Chinese immigrants initially tend to be healthier than the native-born population (Liu, Berhane, \& Tseng, 2010; Rosenmoller et al., 2011). However, existing studies show that this health advantage may diminish over time with Western acculturation.

Immigration to the United States is associated with lifestyle changes related to dietary and physical activity patterns (Satia et al., 2001). The dietary acculturation and physical activity acculturation both contribute to the higher rates of some chronic diseases in Chinese immigrants, including obesity. Obesity, unhealthy diet, and a lack of physical activity are risk factors for cardiovascular disease (CVD), which is the leading cause of death in the U.S. and affects Chinese immigrants disproportionately compared to other ethnic groups in the U.S. population (Wong, Dixon, Gilbride, Kwan, \& Stein, 2013). Therefore, health promotion and disease prevention interventions targeting dietary 
and physical activity acculturation in Chinese immigrants can play an important role in the national health promotion.

A majority of research studies assessing the level of acculturation focus on the general proxy acculturation indicators, such as length of residence, birthplace, generation level, age at arrival, language preference, media and social preferences, and ethnic identification (Satia et al., 2001). Some studies found an association between these measures of acculturation and weight status among immigrant populations, including Chinese immigrants. For example, Yeh et al. (2009) found the length of residence in the U.S. is positively associated with weight status among Chinese Americans. The association between the length of residence and weight status is mediated by the obesityrelated behavioral acculturation. In addition, while these indicators are commonly studied, they may not provide specific information about the dietary acculturation or physical activity acculturation among Chinese immigrants that could be important for designing effective diet or physical activity interventions. However, few studies have examined the effects of both dietary acculturation and physical activity acculturation on weight status among Chinese immigrants. Results of previous studies that have examined dietary acculturation and physical activity acculturation among Chinese immigrants are inconsistent, with various sample sizes differing in age and gender.

\section{Purpose}

The purposes of this study are 1) to investigate the relationships between length of residence in the U.S. and dietary and physical activity acculturation among Chinese 
college students, and 2) to examine the relationships between dietary and physical activity acculturation and weight status among Chinese college students.

\section{Research Hypotheses}

1. Length of residence in the U.S. is associated with dietary and physical activity acculturation.

2. There is a gender difference in physical activity acculturation.

3. Dietary and physical activity acculturation are associated with weight status.

\section{Significance of the Study}

As few studies have examined the relationships between dietary/physical activity acculturation and weight status among Chinese immigrants, this study fills this gap and provides specific information for future interventions. This study also sheds some light on whether the length of residence is associated with weight status, presumably through the dietary and physical activity acculturation. In addition, as the early-years-life in the U.S. plays an important role in dietary and physical activity acculturation, Chinese college students who might live in America for a long time or become Chinese Americans are a population group worth studying.

\section{Definition of Terms}

Acculturation: the cultural modification of an individual, group, or people by adapting to or borrowing traits from another culture, such as customs, traditions, practice or behaviors (Wong et al., 2013). 
Dietary acculturation: generally refers to shifts from traditional diets of vegetables, meats, and whole grains to more processed, high fat, and high sugar foods that are popular and readily available in the U.S. (Wong et al., 2013).

Physical activity acculturation: generally refers to increased frequency of sedentary activities (Wong et al., 2013).

Physical activity: any body movement produced by the contraction of skeletal muscles that result in an expenditure of energy, including activities undertaken while working, playing, carrying out household chores, travelling, and engaging in recreational pursuits (World Health Organization, 2015).

Body mass index (BMI): classification of body weight defined as mass in kilograms divided by the square of the height in meters (World Health Organization, 2015).

\section{Assumptions}

1. The modified dietary acculturation scales were valid measures of dietary acculturation. 2. The International Physical Activity Questionnaire short form (IPAQ-SF) was valid in measuring physical activity of Chinese college students.

3. The self-reported changes in diet and physical activity were valid measures of dietary/physical activity acculturation.

4. All participants answered the questionnaires honestly.

5. The height of participant had not changed since immigration. 


\section{Chapter II}

\section{Review of Literature}

Most immigrants undergo a process of adapting to new social environments in the host country, and the dietary and physical activity acculturation that may occur after immigration could play significant roles in weight status changes. According to Chen, Juon and Lee (2012), results from existing studies that investigated the relationship between acculturation and obesity among immigrant populations are fairly consistent: a higher level of acculturation is associated with increased BMI or higher risks of being overweight or obese. In addition, the level of acculturation is usually assessed by various indirect measures of acculturation including length of residence, birthplace, age at arrival, language preference, or certain acculturation scales.

\section{Weight Status}

A handful of studies examined the association between acculturation and weight status among Chinese immigrants while results are mixed. In these studies, acculturation levels are usually assessed by some common proxy measures, like length of residence. Yeh et al. (2009) reported that Chinese Americans with length of residence in the U.S. no less than 16 years had a significantly higher BMI than those who had live in the U.S. 5 years or less. A similar result was reported in a cross-sectional study of Chinese immigrants in New York City (Afable, Yeh, Trivedi, Andrews, \& Wylie-Rosett, 2016). However, in another cross-sectional study, Wong et al. (2013) found no associations for BMI or WC with length of residence in the U.S. with their 125 older Chinese sample. Another study also suggested no evidence found to support the association between 
duration of time in the U.S. and BMI among Chinese immigrants (Corlin, Woodin, Thanikachalam, Lowe, \& Brugge, 2014).

When looking at BMI/WC change as a weight status indicator, findings of the relationship between length of residence and weight status among Chinese immigrants are also inconsistent. In a previous longitudinal study among Chinese immigrant women, Tseng, Wright and Fang (2015) found that longer U.S. residence was associated with an increase in BMI. However, another longitudinal study with Chinese sample aged 45-84 years found no evidence of greater BMI and WC increases over time among foreign-born Chinese (Albrecht et al., 2013). In addition, Oakkar et al. (2015) found that shorter length of U.S. residence was associated with larger 5-year increases in BMI among foreign-born Asian men, and observed a similar trend among Chinese men.

Previous research suggests that the association between longer length of residence and increased weight or risk of obesity may be in part due to the adoption of unhealthy behaviors after immigration, such as poor dietary patterns and a sedentary lifestyle (Albrecht et al., 2013). Immigration to the U.S. is associated with acculturation-related lifestyle changes, most notably to a shift towards a more westernized diet (Lv \& Cason, 2004; Satia et al., 2001; Tseng et al., 2015).

\section{Dietary Behavior}

Research shows people in China generally have a lower intake of foods that are high in fat while having a higher intake of complex carbohydrates and fiber (Lee et al., 1994; Spindler \& Schultz, 1996; Sun \& Wu, 1997). However, the results of studies on the changes in dietary behavior after immigration are inconsistent. Some studies reported that 
Chinese immigrants adopt a more Western diet with increased consumption of grain products, animal products, dairy products, fats/sweets and vegetables, while others had opposite findings. And as Ro (2014) summarized in a critical review study, the consumption of both healthy and unhealthy food increased over time.

In a study with a Chinese women sample, Satia et al. (2001) found that higher Western dietary acculturation corresponded with higher-fat dietary behaviors, but also increased fruit and vegetable consumption. Consistently, in another cross-sectional study of Chinese Americans in Pennsylvania, Lv and Cason (2004) supported the association between higher acculturation levels (measured by length of residence and English proficiency) and a greater increase in consumption frequency of fats/sweets, fruits and vegetables, while they also found increased consumption of grains, meat/meat alternatives, as well as beverages. In contrast, in a study of Chinese immigrants in Seattle, Taylor et al. (2007) found that a longer length of residence was associated with a lower intake of fruits/vegetables. Findings from Pan, Dixon, Himburg and Huffman (1999) also suggested increased consumption of fats/sweets and fruits after immigration among Asian students (mostly Chinese), but students reported decreased intake of vegetables and meat/meat alternatives. Similarly, in a longitudinal study of Chinese immigrant women, Tseng et al. (2015) reported that acculturation (measured by an abridged version of General Ethnicity Questionnaire - American version) was associated with a less moderate diet (higher energy density, higher percent of energy from fat, and increased sugar intake), and increased intake of red meat, with decreased intake of dark green vegetables and cooked grains. 
However, inconsistent with all the above findings in regards to fat intake, other studies suggested that Chinese immigrants have a decreased fat intake by reducing the consumption of fried foods (Kwok, Mann, Wong, \& Blum, 2009; Rosenmoller et al., 2011). Rosenmoller et al. (2011) also found associations between length of residence and unfavorable changes, such as consuming significant greater portion sizes, dining out more frequently, and consuming convenience food more often, in Chinese immigrants in Canada. Similarly, Liu et al. (2010) investigated the dietary quality among Chinese women, and as well found both favorable and unfavorable dietary changes. They concluded that more acculturated (assessed by English proficiency and social interactions) Chinese immigrants have improved dietary variety and adequacy while having lower dietary moderation. They suggested the diminished dietary moderation as an acculturation-related dietary change may predispose Chinese immigrants to a higher chronic disease risk.

Studies that examined the effects of dietary acculturation among Chinese immigrants also have inconsistent findings. Chen et al. (2012) investigated the association between several measures of acculturation, including food preference at home and in restaurants, and BMI among Asian Americans (Chinese, Korean and Vietnamese adults), and found the equal preference of Asian vs. American food in restaurants is significantly associated with increased BMI. In a mixed method research, Wu and Smith (2016) reported that Chinese students who ate more American foods were more likely to experience weight gain. On the other hand, Oster and Yung (2010) conducted a crosssectional study to investigate the association between acculturation, BMI, physical 
activity and fasting glucose among Chinese immigrants, and concluded that adoption of Western diet may not predispose immigrants to obesity. Moreover, they suggested "interventions targeting weight maintenance and physical activity rather than specific dietary practices may be most effective" (Oster \& Yung, 2010, p. 109).

\section{Physical Activity}

In terms of physical activity, Kandual and Lauderdale (2005) found that Asian Americans were much more likely to be physically inactive than U.S.-born non-Asians. Results of how physical activity pattern change over time in Asian immigrants were mixed. Unger et al. (2004) pointed out that higher acculturation (assessed with the AHIMSA acculturation scale and a language scale) was associated with less physical activity among Asian American adolescents. However, in a population-based study, Kandual and Lauderdale (2005) found a positive association between length of residence and increased likelihood of meeting recommended leisure time physical activity in foreign-born Asian Americans. Similarly, in a cross-sectional study of Chinese immigrants in New York City, Afable et al. (2016) found that longer length of residence was associated with a greater likelihood of leisure time physical activity, but also lower likelihood of work related physical activity. In addition, Taylor et al. (2007) reported that Chinese immigrants in Seattle with longer length of residence were less physically active than their more recently immigrated counterparts. Furthermore, Wong et al. (2013) found that low, moderate and vigorous-intensity physical activity did not differ by length of residence in America according to their older Chinese immigrant sample. 
Though it is unclear about the physical activity pattern change after immigration, as Monda, Adair, Zhai and Popkin (2008) stated, reduction in physical activity has important implications for weight gain. However, existing studies rarely examined the effects of physical activity acculturation on weight status among Chinese immigrants. A cross-sectional study of Brazilian, Haitian and Latino immigrants, Tovar et al. (2014) found that the degree of self-reported physical activity change since immigrating to the U.S. was associated with BMI. Yan and Cardinal (2013) investigated the perception and barriers of physical activity participation among Chinese female graduate students. They suggested that the environmental resources available on campus that facilitate physical activity are not enough to promote physical activity among Chinese female graduate students due to various barriers, such as a lack of knowledge and skills. As a result, there is a gap in knowledge about the influence of physical activity acculturation among Chinese immigrants; they do not adapt to American exercise culture with the intended physical activity, but are affected by the "obesogenic" environment with less walking, bicycling and stair climbing opportunities.

\section{Summary}

Despite mixed findings, existing studies largely focus on examining the relationships between length of residence and weight status or changes in diet and physical activity in Chinese immigrants, rather than how immigration-related dietary and physical activity changes may affect weight status. In these studies, either BMI or change in BMI was used as the weight status indicator. Studies investigating dietary changes in Chinese immigrants mainly emphasized changes in what they eat rather than changes in 
when and how much they eat. In addition, only a few studies focused on young adults, even though younger Chinese adult immigrants were found to acculturate at a faster rate than their older counterparts (Cheung, Chudek, \& Heine, 2011). 


\section{Chapter III}

\section{Methods}

\section{Study Design}

This is a cross-sectional study with 55 Chinese college students as participants. Anthropometric data included measured height and weight, and self-reported weight change since immigration. Length of residence in the U.S., and dietary and physical activity acculturation were measured using self-report questionnaires.

\section{Participants}

A convenience sample of 60 (30 males and 30 females) volunteer Chinese college students were recruited from Portland State University. Eligibility criteria required study participants to be non-pregnant Chinese students at least 18 years of age with a length of residence in the U.S. $\geq 3$ months. Potential participants were identified via the Portland State Office of International Affairs, Chinese Student Scholar Association and Hong Kong Student Association at the university, and then reached via e-mail, or in-person. Information about this study was also posted on Chinese social media platforms. If the student expressed interest in participating, an appointment was then scheduled to meet, and they were encouraged to bring their Chinese friends (who were also willing to participate) to the meeting. In an effort to improve subject recruitment, participants were eligible for a drawing of five \$10 gift cards upon completion of the study. Human Subjects approval for this study was granted by the PSU Human Subjects Research Review Committee. 


\section{Equipment}

Equipment used for anthropometric data included a stadiometer to measure standing height, a physician's bodyweight scale for measuring bodyweight, and a flexible plastic measuring tape to measure waist circumference. Information regarding sociodemographic characteristics, dietary/physical activity acculturation, current physical activity and self-reported changes in diet, physical activity and weight status was obtained using questionnaires (Appendix A).

The dietary acculturation scales (including a 6-item Chinese dietary scale and a 10-item Western dietary scale) was a modified version of a previously validated scale developed by Satia et al. (2001). Current physical activity was assessed using the International Physical Activity Questionnaire short form (IPAQ-SF). Additional questions about self-reported changes in diet, physical activity and weight status (Tovar et al., 2014; Rosenmoller et al., 2011) was were also included as the fourth section of the survey.

In section four, self-reported changes of portion size and meal sizes (including breakfast, lunch and dinner) were used as dietary acculturation indicators. Self-reported changes of physical activity time (including running, bicycling, stair-climbing and walking) and sedentary time were used as physical activity acculturation indicators. Environmental factors (e.g., food accessibility/affordability and physical activity accessibility) and perceived influence of environmental factors (such as unhealthy food accessibility and walking accessibility) on health-related behaviors (including food choices and physical activity time) were collected to explore their utility as potential 
explanations for behavior changes. The perceived influence of behavior changes (including dietary changes and physical activity changes) on weight status were collected to examine their role in weight status changes.

\section{Variables}

Independent variables included 1) length of residence, 2) gender, 3) dietary acculturation, and 4) physical activity acculturation. Dependent variables included 1) dietary acculturation, 2) physical activity acculturation, 3) body mass index (BMI), 4) BMI change, and 5) waist circumference (WC). Uncontrolled variables included 1) age, 2) smoking status, 3) marital status, 4) education level, and 5) self-identity.

\section{General Procedures}

The purpose and procedures of the study were comprehensively explained to all participants. Written informed consent was obtained from each participant prior to their inclusion in the study protocol.

Height (without shoes) and waist circumferences (WC) were measured to the nearest $0.1 \mathrm{~cm}$. Bodyweight was measured in light clothes, without shoes, to the nearest 0.01 kilogram. Body mass index (BMI) was calculated according to recommendations of the Western Pacific Region of the World Health Organization (WHO) Steering Committee, using the following cut-points: underweight $=$ BMI $<18.5 \mathrm{~kg} / \mathrm{m}^{2} ;$ normal weight $=18.5 \leq \mathrm{BMI}<23 \mathrm{~kg} / \mathrm{m}^{2} ;$ overweight $=23 \leq \mathrm{BMI}<25 \mathrm{~kg} / \mathrm{m}^{2} ;$ and obesity $=$ BMI $\geq 25 \mathrm{~kg} / \mathrm{m}^{2}$ (Wong et al., 2013). Waist circumstance (WC) cut-points were as follows: visceral adiposity $=\mathrm{WC} \geq 90 \mathrm{~cm}$ (male) and $\mathrm{WC} \geq 80 \mathrm{~cm}$ (female) (LêScherban, Albrecht, Osypuk, Sánchez, \& Diez Roux, 2014; Wong et al., 2013). 
After completing anthropometric measurements, a diet and physical activity acculturation survey (appendix A) was distributed to collect socio-demographic data (e.g., age, gender, education level, the length of residence, marital status, smoking status, self-identity and pregnancy status), and to measure dietary acculturation, current physical activity and additional self-reported changes in diet, physical activity and weight status.

\section{Statistical Analysis}

After excluding U.S.-born participants and participants with length of residence less than 3 months, data from 55 participants (28 males and 27 females) were used in the analyses. Descriptive statistics were used to assess the distribution of sociodemographic and anthropometric characteristics, and to describe the reported dietary and physical activity changes. Length of residence in years was dichotomized into two categories (i.e., $\leq 2$ years and $>2$ years) for descriptive data presentation. Length of residence in months was used as a continuous variable (bivariate correlation) in assessing the relationships with acculturation/weight status. Weight change was classified into three categories ("weight gain" = gain of $>2.5 \mathrm{~kg}$; "weight loss" = loss of $>2.5 \mathrm{~kg}$; "no change" = gain or loss of $<2.5 \mathrm{~kg}$ ). BMI change was calculated based on the self-reported weight change since immigration and the measured current height and weight.

All questions regarding dietary and physical activity changes were based on a 5point Likert-scale ( 1 = "much less", 3 = "no change", 5 = "much more"). For analysis and presentation purposes, results were grouped in three categories: decreased change/less often (combined responses of 1 and 2), no change (response 3) and increased change/more often (combined responses of 4 and 5). In the Chinese dietary scale, "Total 
Chinese items" was calculated by summing up all 6-sub-item responses (6-17 = "less", $18=$ "no change", 19-30 = "more"). Similarly, in the Western dietary scale, "Total Western items" was calculated by summing up all 10-sub-item responses (10-29= "less", $30=$ "no change", $31-50=$ "more"). All questions regarding the perceived influence of environmental factors/behavior changes on health-related behaviors/weight status were also based on a 5-point Likert-scale ( 1 = "not at all", 5 = "very likely").

Western dietary score was dichotomized at the approximate median to represent lower $(\leq 35)$ and higher $(>35)$ levels of Western acculturation. Chinese dietary score was dichotomized at the approximate median to represent lower $(\leq 15)$ and higher $(>15)$ levels of maintenance of Chinese dietary patterns. Total amount of physical activity (MET-minutes/week) was estimated according to the official IPAQ-SF scoring protocol (version 2.0.). MET values for vigorous-intensity physical activities, moderate-intensity physical activities, and walking are 8.0, 4.0, and 3.3, respectively. Statistical procedures included independent t-tests, Chi-square tests, and bivariate correlation. A p-value of < 0.05 was used to denote statistical significances. 


\section{Chapter IV}

\section{Results}

\section{Socio-demographic and Anthropometric Characteristics}

Table 1 shows the socio-demographic and anthropometric characteristics of the entire study sample as well as by length of residence sub-groups. The mean length of residence was $34.4 \pm 34.4$ months and the mean age was $23.8 \pm 3.7$ years. A majority of the participants were undergraduate students $(61.6 \%)$, and most of them were unmarried (92.7\%), non-smokers (87.3\%) and identified themselves as Chinese (94.6\%). The mean BMI and WC were $22.3 \pm 3.2 \mathrm{~kg} / \mathrm{m}^{2}$ and $79.7 \pm 10.0 \mathrm{~cm}$, respectively for all participants. Compared with the national mean WC $(79.5 \mathrm{~cm})$ from the 2014 National Physique Monitoring Report (from the General Administration of Sport of China), male participants (20 24 years old) had a significantly higher mean WC $(86.3 \pm 8.4 \mathrm{~cm})(\mathrm{not}$ shown in Table 1).

More than one third (37.2\%) of participants were overweight or obese. It is worth noting that participants with length of residence longer than 2 years had a much higher percentage of being classified as obese compared with those who resided in the U.S. 2 years or less (32.3\% vs. 8.3\%). Nearly $50 \%$ of participants reported an increase in weight (> $2.5 \mathrm{~kg}$ ) since coming to the U.S. Percentages of participants experiencing weight gain for the length of residence sub-groups ( $>2$ years and $\leq 2$ years) were $61.5 \%$ and $34.8 \%$, respectively. The mean BMI change for the total sample was $0.6 \pm 1.9 \mathrm{~kg} / \mathrm{m}^{2}$. Length of residence was significantly correlated with BMI change $(r=0.33)$ for all participants, but gender sub-group analysis showed that it was true only for males $(r=0.42)$. 
Table 1. Socio-demographic and anthropometric characteristics

\begin{tabular}{|c|c|c|c|}
\hline & \multirow[b]{2}{*}{ Total $(n=55)$} & \multicolumn{2}{|c|}{ Length of residence } \\
\hline & & $\leq 2$ years $(n=24)$ & $>2$ years $(n=31)$ \\
\hline LOR (months) ${ }^{a}$ & $34.40 \pm 34.44$ & $10.67 \pm 6.66$ & $52.77 \pm 36.08$ \\
\hline Age (years) & $23.84 \pm 3.68$ & $23.83 \pm 3.71$ & $23.84 \pm 3.71$ \\
\hline \multicolumn{4}{|l|}{ Marital status } \\
\hline Married ${ }^{b}$ & $4(7.27)$ & $2(8.33)$ & $2(6.45)$ \\
\hline Unmarried & $51(92.73)$ & $22(91.67)$ & $29(93.55)$ \\
\hline \multicolumn{4}{|l|}{ Educational level } \\
\hline Undergraduate & $34(61.62)$ & $12(50.00)$ & $22(70.97)$ \\
\hline Post-bac & $3(5.45)$ & $3(12.50)$ & $0(0.00)$ \\
\hline Graduate & $18(32.73)$ & $9(37.50)$ & $9(29.03)$ \\
\hline \multicolumn{4}{|l|}{ Smoking status } \\
\hline Non-smoker & $48(87.27)$ & $22(91.67)$ & $26(83.87)$ \\
\hline Current-smoker & $6(10.91)$ & $2(8.33)$ & $4(12.90)$ \\
\hline Former smoker & $1(1.82)$ & $0(0.00)$ & $1(3.23)$ \\
\hline \multicolumn{4}{|l|}{ Self-identity } \\
\hline Chinese & $52(94.55)$ & $24(100.00)$ & $28(90.32)$ \\
\hline American & $0(0.00)$ & $0(0.00)$ & $0(0.00)$ \\
\hline Equal $^{\mathrm{c}}$ & $3(5.45)$ & $0(0.00)$ & $3(9.68)$ \\
\hline $\operatorname{BMI}\left(\mathrm{kg} / \mathrm{m}^{2}\right)$ & $22.29 \pm 3.20$ & $21.43 \pm 2.64$ & $22.96 \pm 3.46$ \\
\hline Underweight & $6(10.91)$ & $3(12.50)$ & $3(9.68)$ \\
\hline Normal weight & $28(50.91)$ & $15(62.50)$ & $13(41.94)$ \\
\hline Overweight & $9(16.36)$ & $4(16.67)$ & $5(16.13)$ \\
\hline Obesity & $12(21.82)$ & $2(8.33)$ & $10(32.26)$ \\
\hline $\mathrm{WC}(\mathrm{cm})$ & $79.65 \pm 10.00$ & $76.88 \pm 8.48$ & $81.80 \pm 10.67$ \\
\hline Visceral adiposity & $13(23.64)$ & $4(16.67)$ & $9(29.03)$ \\
\hline \multicolumn{4}{|l|}{$\Delta$ Weight } \\
\hline Weight gain & $24(48.98)$ & $8(34.78)$ & $16(61.54)$ \\
\hline Weight loss & $8(16.33)$ & $4(17.39)$ & $4(15.38)$ \\
\hline$\sim$ No change & $17(34.69)$ & $11(47.83)$ & $6(23.08)$ \\
\hline$\Delta \mathrm{BMI}\left(\mathrm{kg} / \mathrm{m}^{2}\right)^{*}$ & $0.58 \pm 1.88$ & $0.19 \pm 1.36$ & $0.92 \pm 2.20$ \\
\hline
\end{tabular}

Note. $\mathrm{LOR}=$ length of residence; $\mathrm{BMI}=$ body mass index; $\mathrm{WC}=$ weight circumference; underweight $=\mathrm{BMI}<18.5$; normal weight $=18.5 \leq \mathrm{BMI}<23$; overweight $=23 \leq \mathrm{BMI}<25$; obesity $=\mathrm{BMI} \geq 25$; visceral adiposity $=\mathrm{WC}($ male $) \geq 90 \mathrm{~cm}$ and $\mathrm{WC}($ female $) \geq 80 \mathrm{~cm}$.

Sample sizes vary slightly due to missing data.

${ }^{\mathrm{a}}$ mean $\pm \mathrm{SD}$.

${ }^{\mathrm{b}} \mathrm{n}(\%)$.

${ }^{c}$ identifying oneself as both Chinese and American equally.

*correlation, $\mathrm{p}<0.05$. 


\section{Dietary Acculturation}

As shown in Figure 1-a, more than $80 \%$ of participants reported a decrease in their Chinese dietary items/habits, as indicated by "Total Chinese items." Specifically, more than $70 \%$ of participants reported a decrease in having a Chinese-style breakfast in the past month compared with that they had in China, and more than $50 \%$ of participants reported a decrease of eating traditionally preserved food as well as eating on time. About $50 \%$ of participants reported a decrease of eating tofu and in balancing yin/yang food. Item responses regarding Western dietary items/habits are shown in Figure 1-b. Overall, $80 \%$ of participants reported an increase in their Western dietary items/habits, as indicated by "Total Western Items." Nearly $70 \%$ of participants reported eating more at Western fast-food restaurants, and more than $60 \%$ of participants reported an increased consumption of bread, rolls, bagels, cheese, milk products, ground beef and hamburgers. About $60 \%$ of participants reported eating more pizza and spaghetti, nearly $50 \%$ of participants reported an increased consumption of sweets, cakes or pies for dessert, and $40 \%$ of participants reported eating more packaged or prepared food. 
(a) $\square$ Less $\square$ No change $\square$ More

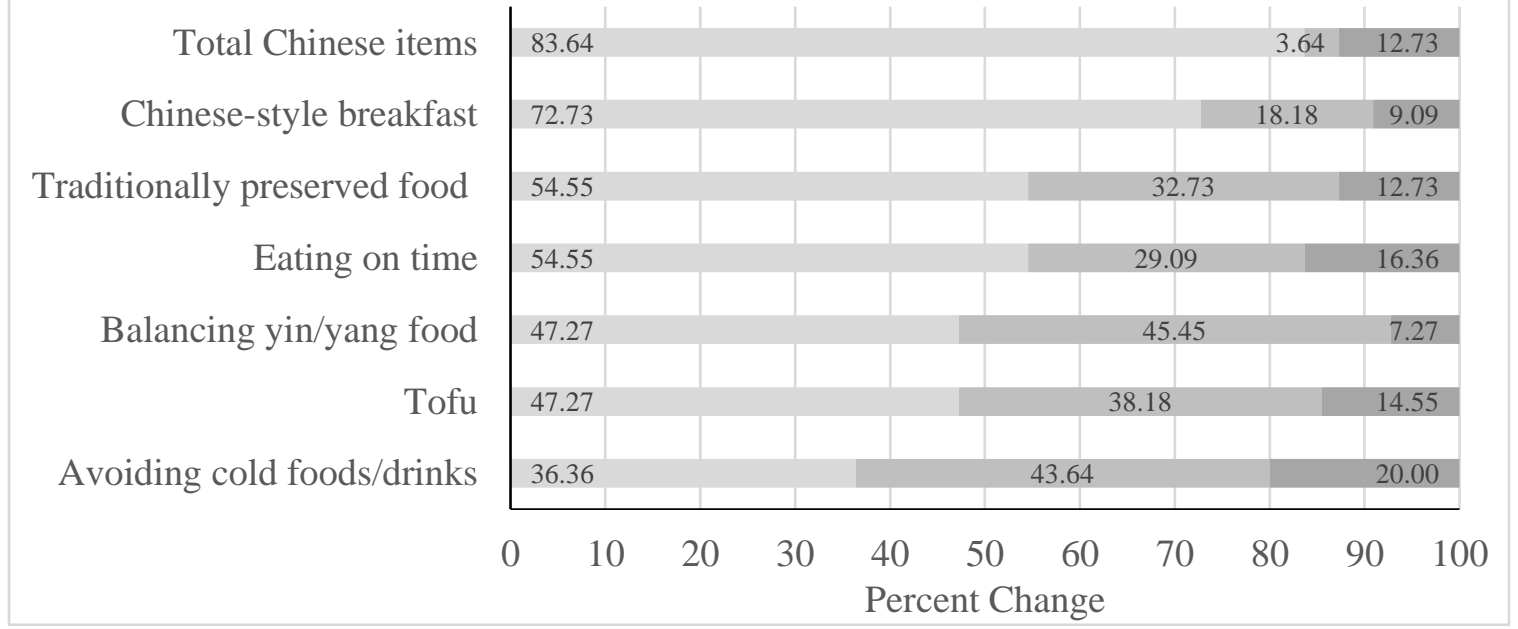

(b)

$$
\square \text { Less } \square \text { No change } \square \text { More }
$$

Total Western items

Eating at Western fast-food restaurants Bread/rolls/bagels Any kind of cheese Milk products

Ground beef and hamburgers $\mathrm{Pizza} /$ spaghetti with tomato sauce Sweets/cakes/ pies for dessert Packaged/prepared food Eating between meals Carbonated beverages

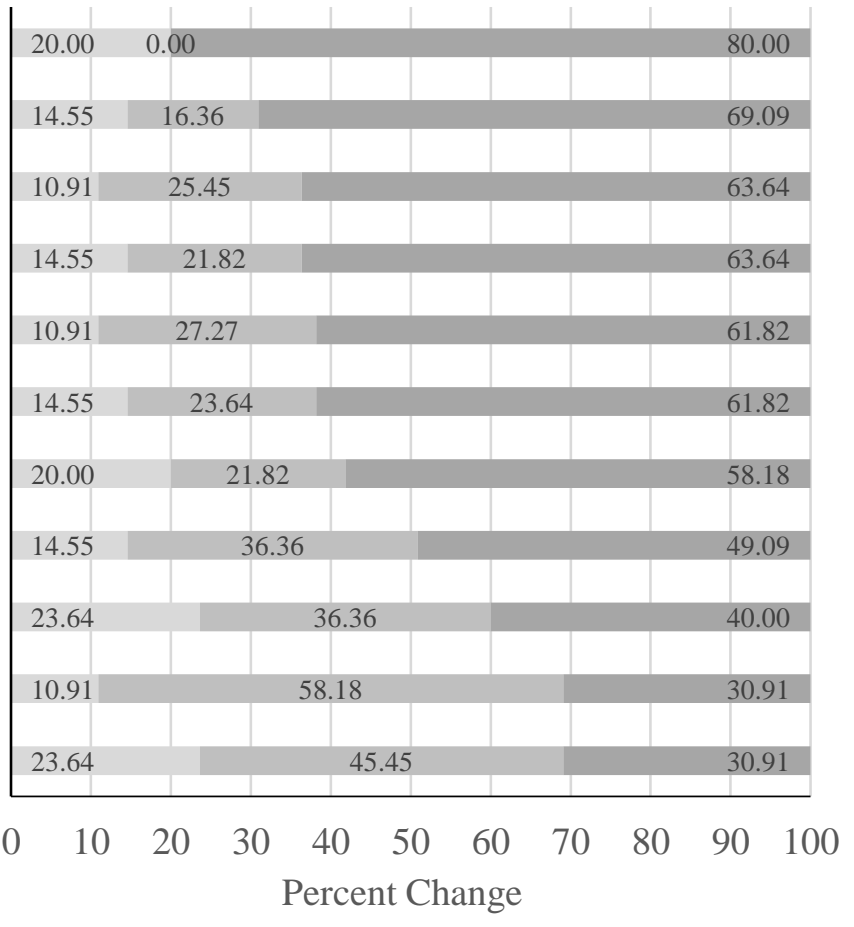

Figure 1. Percentages of reported changes of Chinese (a) and Western (b) items in dietary acculturation scales

Figure 2 shows percentages of additional dietary changes reported by participants. No more than $50 \%$ percent of participants reported having unchanged portion size or 
meal sizes. About one third of the participants reported an increased portion size. More than $35 \%$ of participants reported an increased dinner size while nearly $55 \%$ of participants reported a decreased breakfast size.

More than $70 \%$ of participants reported that unhealthy food accessibility had increased since immigration, while only about $45 \%$ of participants reported an increase in the accessibility of healthy food. In addition, almost $50 \%$ of participants reported that unhealthy food is more affordable in the U.S., while similar percentages of participants reported that healthy food affordability was increased (38\%) or decreased (36\%) (Figure 2). In addition, most participants $(80 \%-87 \%)$ reported that the immigration-related changes of healthy/unhealthy food accessibility/affordability affected their food choices (results not shown).

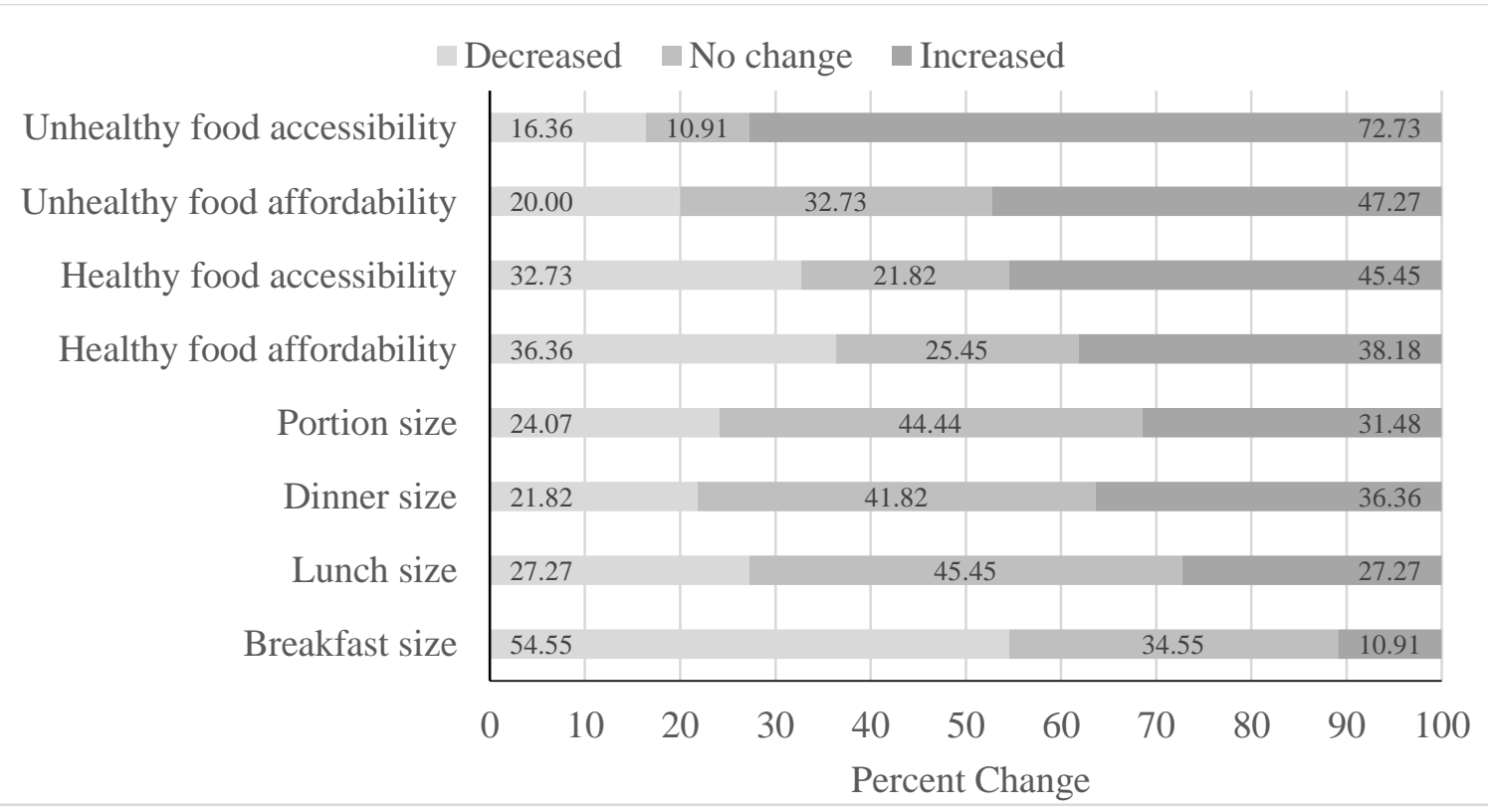

Figure 2. Percentages of reported changes of other dietary items 


\section{Physical Activity Acculturation}

Overall, nearly $50 \%$ of participants reported they felt that both vigorous and moderate physical activity accessibility are higher in the U.S. (Figure 3). Figure 3 also shows how participants felt the time they spent in running, walking, bicycling, stair climbing and sedentary behaviors changed. Nearly 50\% reported an increased sedentary time, an increased walking time, a decreased bicycling time and a decreased stair climbing time. In addition, about $45 \%$ reported no change in the time spent running, whereas nearly $35 \%$ of the participants reported an increased running time.

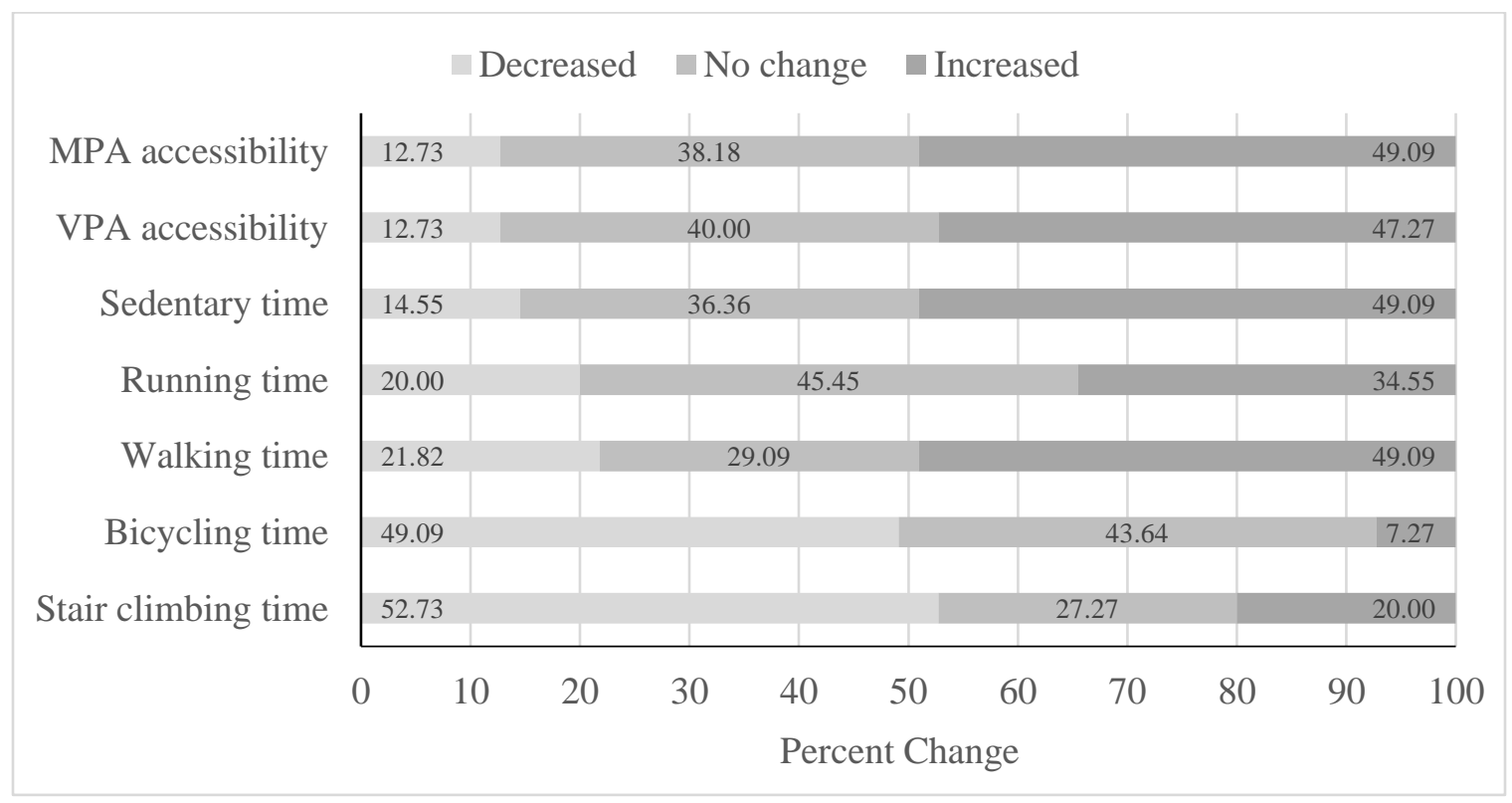

Figure 3. Percentages of reported changes in PA accessibility and time

Furthermore, $80 \%$ of participants reported that their walking/stair-climbing time was affected by the change of walking/stair-climbing accessibility. A majority of participants $(73 \%)$ felt the change in running accessibility affected their running time, and $62 \%$ of participants reported the change in bicycling accessibility affected their 
bicycling time. However, it is unclear whether their perceived changes in physical activity accessibility affected their physical activity time positively or negatively (results not shown).

\section{Gender Difference in Physical Activity Acculturation}

Independent t-test analysis revealed no significant gender differences in the time changes that males and females reported spending on running, bicycling, stair-climbing, walking and sedentary behaviors (Figure 4).

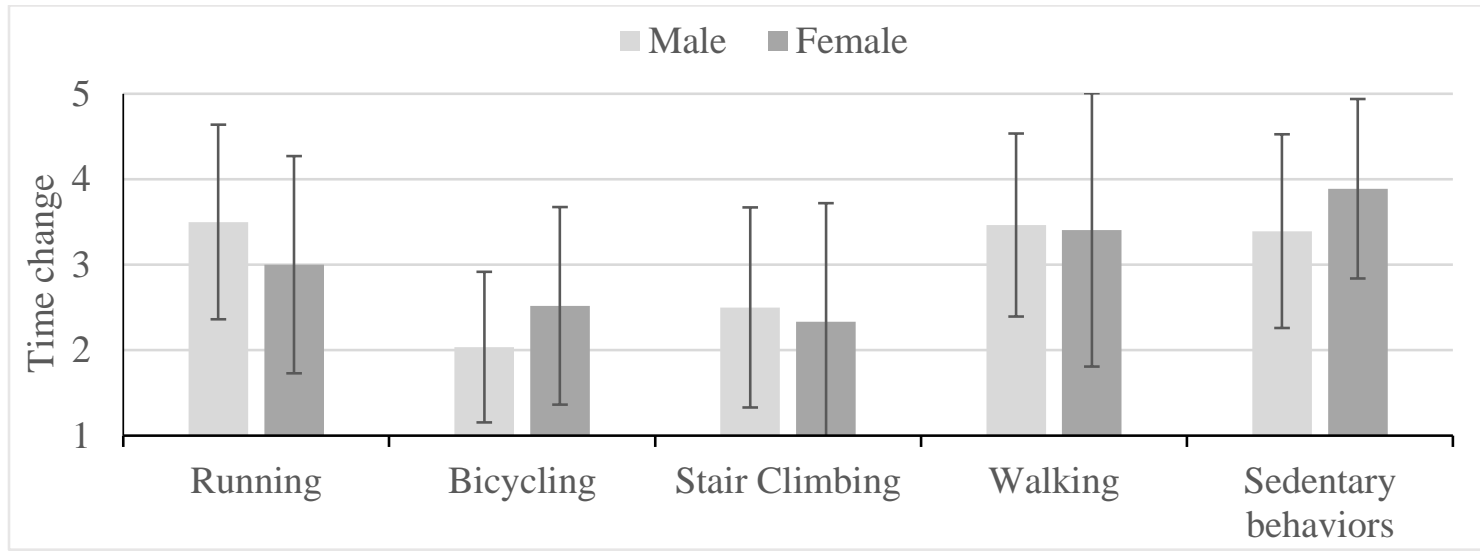

Figure 4. Changes in time spent on running, bicycling, stair-climbing, walking and sedentary behaviors by gender

\section{Length of Residence and Dietary and Physical Activity Acculturation}

Table 2 presents results that show dietary and physical activity acculturation and current physical activity level of all participants as well as by length of residence subgroups. Approximately one-half (52\%) of participants reported a lower level of Chinese diet maintenance, and $56 \%$ of participants reported a higher level of Western dietary acculturation. It appears that participants with length of residence longer than 2 years were more likely to have a decreased breakfast size (68\% vs. $38 \%)$ and have increase 
sedentary time (61\% vs. $33 \%)$. In addition, according to the IPAQ-SF score, participants in both length of residence sub-groups met the moderate physical activity level (achieving a minimum total PA of at least 600 MET-minutes/week) but neither met the high physical activity level (achieving a minimum total PA of at least 3000 METminutes/week).

Table 2. Length of residence and dietary and PA acculturation

\begin{tabular}{llll}
\hline & & \multicolumn{2}{c}{ Length of residence } \\
\cline { 3 - 4 } \multicolumn{1}{c}{ Diet } & Total $(\mathrm{n}=55)$ & $\leq 2$ years $(\mathrm{n}=24)$ & $>2$ years $(\mathrm{n}=31)$ \\
Chinese diet score $<15^{\mathrm{a}}$ & $29(52.27)$ & $12(50.00)$ & $17(54.84)$ \\
Western diet score $>35$ & $31(56.36)$ & $14(58.33)$ & $17(54.84)$ \\
Portion size $\uparrow$ & $17(31.48)$ & $6(25.00)$ & $11(36.67)$ \\
Breakfast size $\downarrow$ & $30(54.55)$ & $9(37.50)$ & $21(67.74)$ \\
Lunch size $\uparrow$ & $15(27.27)$ & $5(20.83)$ & $10(32.26)$ \\
Dinner size $\uparrow$ & $20(36.36)$ & $9(37.50)$ & $11(35.48)$ \\
$\quad$ Physical activity & & & \\
$\Delta$ PA time & & & $7(22.58)$ \\
Running $\downarrow$ & $11(20.00)$ & $4(16.67)$ & $14(45.16)$ \\
Bicycling $\downarrow$ & $27(49.09)$ & $13(54.17)$ & $18(58.06)$ \\
Stair climbing $\downarrow$ & $29(52.73)$ & $11(45.83)$ & $9(29.03)$ \\
Walking $\downarrow$ & $12(21.82)$ & $3(12.50)$ & $19(61.29)$ \\
Sedentary behaviors $\uparrow$ & $27(49.09)$ & $8(33.33)$ & $2386.61 \pm 1901.91$ \\
Total PA (MET-min/wk) & $2182.07 \pm 1767.23$ & $1909.36 \pm 1622.23$ & $457.24 \pm 132.64$ \\
Sitting (min/d) & $471.00 \pm 148.24$ & $490.00 \pm 169.00$ & \\
\hline Sampl & & &
\end{tabular}

Sample sizes vary slightly due to missing data.

a $\mathrm{n}(\%)$.

${ }^{\mathrm{b}}$ mean $\pm \mathrm{SD}$.

Table 3 shows correlations between length of residence in the U.S. and selfreported changes in portion size/self-reported total amount of physical activity for the total sample as well as for each gender. Length of residence was significantly correlated with portion size $(r=0.51)$ and total amount of physical activity $(r=0.45)$ only among males. There were no significant correlations between any other acculturation variables 
and length of residence for all participants (Pearson correlation coefficients ranged from 0.26 to 0.26 ) (results not shown).

Table 3. Correlation between length of residence and portion size/total PA

\begin{tabular}{lccc}
\hline & \multicolumn{3}{c}{ Length of residence } \\
\cline { 2 - 4 } & Total $(\mathrm{n}=55)$ & Male $(\mathrm{n}=28)$ & Female $(\mathrm{n}=27)$ \\
\hline Portion size & 0.22 & $0.51^{*}$ & 0.08 \\
Total PA (MET-min/wk) & 0.07 & $0.45^{*}$ & -0.07 \\
\hline
\end{tabular}

Sample sizes vary slightly due to missing data.

$* \mathrm{p}<0.05$.

\section{Dietary Acculturation and Weight Status}

Table 4 shows the relationship between Chinese/Western dietary acculturation and weight status for all participants. Although participants with lower Chinese dietary scores appeared more likely to experience weight gain (56\% vs. $42 \%)$, there was no statistically significant difference in weight status whether or not participants adhered to a Chinese diet. Participants with higher Western dietary scores were significantly more likely to demonstrate weight gain.

Table 4. Chinese/Western dietary acculturation and weight status

\begin{tabular}{|c|c|c|c|c|}
\hline & \multicolumn{2}{|c|}{ Chinese items } & \multicolumn{2}{|c|}{ Western items } \\
\hline & $\begin{array}{c}\text { Score }<15 \\
(\mathrm{n}=29)\end{array}$ & $\begin{array}{c}\text { Score } \geq 15 \\
(\mathrm{n}=26)\end{array}$ & $\begin{array}{c}\text { Score } \leq 35 \\
(\mathrm{n}=24)\end{array}$ & $\begin{array}{c}\text { Score }>35 \\
(\mathrm{n}=31)\end{array}$ \\
\hline $\operatorname{BMI}\left(\mathrm{kg} / \mathrm{m}^{2}\right)^{\mathrm{a}}$ & $22.44 \pm 2.81$ & $22.13 \pm 3.42$ & $21.59 \pm 3.43$ & $22.83 \pm 2.95$ \\
\hline Overweight/obesity ${ }^{\mathrm{b}}$ & $11(37.93)$ & $10(38.46)$ & $8(33.33)$ & $13(41.94)$ \\
\hline $\mathrm{WC}(\mathrm{cm})$ & $80.20 \pm 8.97$ & $79.04 \pm 11.18$ & $78.88 \pm 10.33$ & $80.25 \pm 9.86$ \\
\hline Visceral adiposity & $6(20.69)$ & $7(26.92)$ & $6(25.00)$ & $7(22.58)$ \\
\hline$\Delta \mathrm{BMI}\left(\mathrm{kg} / \mathrm{m}^{2}\right)$ & $0.97 \pm 1.68$ & $0.18 \pm 2.01$ & $0.20 \pm 1.54$ & $0.91 \pm 2.10$ \\
\hline Weight gain $(>2.5 \mathrm{~kg})$ & $14(56.00)$ & $10(41.67)$ & $7(30.43)$ & $17(65.38)^{*}$ \\
\hline $\begin{array}{l}\text { Note. } \mathrm{BMI}=\text { body mass in } \\
\text { circumference; Visceral a } \\
\text { Sample sizes vary slightly } \\
{ }^{\mathrm{a}} \text { mean } \pm \mathrm{SD} \text {. } \\
\mathrm{b} \mathrm{n}(\%) \text {. } \\
{ }^{*} \text { Chi-square, } \mathrm{p}<0.05 \text {. }\end{array}$ & $\begin{array}{l}\mathrm{x} ; \text { Overweigl } \\
\text { osity }=\mathrm{WC} \\
\text { e to missing }\end{array}$ & $\begin{array}{l}\text { esity }=\text { BMI } \geq \\
\geq 90 \mathrm{~cm} \text { and }\end{array}$ & $\begin{array}{l}/ \mathrm{m}^{2} ; \mathrm{WC}=\mathrm{w} \\
\text { female) } \geq 80\end{array}$ & \\
\hline
\end{tabular}


Table 5 shows correlations between several other dietary acculturation indicators and weight status (BMI/WC/BMI change) for the total sample as well as for each gender. Perceived change in portion size was significantly correlated with BMI change for all participants $(r=0.44)$ and this was true for both males $(r=0.53)$ and females $(r=0.39)$. Reported change in lunch size was positively correlated with the change in BMI in males $(r=0.57)$ while negatively correlated with BMI change in females $(r=-0.42)$. Reported change in dinner size was significantly correlated with the change in BMI for all participants $(r=0.37)$, but gender sub-group analysis showed that it was true only for males $(r=0.49)$.

Table 5. Correlation between dietary acculturation indicators and weight status

\begin{tabular}{|c|c|c|c|c|c|c|c|c|c|}
\hline & \multicolumn{3}{|c|}{ BMI $\left(\mathrm{kg} / \mathrm{m}^{2}\right)$} & \multicolumn{3}{|c|}{$\mathrm{WC}(\mathrm{cm})$} & \multicolumn{3}{|c|}{$\Delta \mathrm{BMI}\left(\mathrm{kg} / \mathrm{m}^{2}\right)$} \\
\hline & Total & Male & Female & Total & Male & Female & Total & Male & Female \\
\hline Portion size & 0.23 & 0.38 & 0.17 & 0.09 & 0.18 & 0.13 & $0.44^{*}$ & $0.53 *$ & $0.39 *$ \\
\hline Breakfast size & 0.01 & 0.21 & -0.07 & -0.12 & 0.19 & -0.30 & 0.06 & 0.22 & -0.10 \\
\hline Lunch size & 0.14 & 0.28 & 0.12 & 0.06 & 0.26 & 0.02 & 0.00 & $0.57 *$ & $-0.42 *$ \\
\hline Dinner size & -0.09 & 0.08 & -0.08 & -0.16 & -0.09 & -0.03 & $0.37 *$ & $0.49 *$ & 0.35 \\
\hline
\end{tabular}

\section{Physical Activity Acculturation and Weight Status}

Table 6 shows correlations between physical activity acculturation indicators and weight status (BMI/WC/BMI change) for the total sample as well as for each gender. Similar to the percentage for dietary behaviors change, $89 \%$ of participants reported that their physical activity change since immigration affected their weight status (results not shown). However, no statistically significant correlations were observed between any physical activity indicators (changes in running, bicycling, stair-climbing, walking and sedentary time) and weight status (Table 6). 
Table 6. Correlation between PA acculturation indicators and weight status

\begin{tabular}{|c|c|c|c|c|c|c|c|c|c|}
\hline & \multicolumn{3}{|c|}{ BMI $\left(\mathrm{kg} / \mathrm{m}^{2}\right)$} & \multicolumn{3}{|c|}{$\mathrm{WC}(\mathrm{cm})$} & \multicolumn{3}{|c|}{$\Delta \mathrm{BMI}\left(\mathrm{kg} / \mathrm{m}^{2}\right)$} \\
\hline & Total & Male & Female & Total & Male & Female & Total & Male & Female \\
\hline Running & 0.19 & 0.15 & 0.07 & 0.18 & 0.05 & 0.08 & -0.19 & -0.34 & -0.11 \\
\hline Bicycling & 0.01 & 0.01 & 0.28 & -0.01 & 0.05 & 0.30 & 0.09 & 0.03 & 0.21 \\
\hline Stair-climbing & -0.06 & -0.05 & -0.17 & 0.02 & -0.06 & 0.00 & 0.00 & -0.08 & 0.06 \\
\hline Walking & -0.04 & -0.22 & 0.10 & 0.07 & -0.15 & 0.27 & 0.02 & -0.22 & 0.21 \\
\hline Sedentary time & -0.10 & -0.06 & 0.09 & -0.20 & -0.01 & -0.17 & -0.05 & -0.15 & 0.13 \\
\hline
\end{tabular}

Note. BMI = body mass index; $\mathrm{WC}=$ weight circumference.

Sample sizes vary slightly due to missing data. 


\section{Chapter V}

\section{Discussion}

The goals of this study were to investigate the relationships between dietary acculturation, physical activity acculturation and length of U.S. residence as well as weight status among Chinese college students. The study results revealed the following major findings: (1) length of residence in the U.S. was positively correlated with larger portion size, greater amount of physical activity and increases in BMI in male participants; (2) adoption of a Western diet was associated with weight gain; (3) portion size change was positively correlated with BMI change; and (4) lunch size change and dinner size change were positively correlated with BMI change in males, and lunch size change was negatively correlated with BMI change in females.

\section{Length of Residence and Dietary/Physical Activity Acculturation}

In this study, Chinese college students increased consumption of Western foods while consumption of traditional Chinese foods decreased after immigration. These results agree with findings from a previous study conducted with Chinese Americans in Pennsylvania (Lv \& Cason, 2004). They are also consistent with Rosenmoller et al. (2011), who found that compared to Chinese immigrants who lived in Canada the shortest, Chinese immigrants who lived in Canada the longest consumed significantly greater portion sizes. The current study revealed a positive correlation between length of residence in the U.S. and portion size in male participants. One possible explanation for the larger portion size could be that larger portion sizes are more readily accessible in shops and restaurants in the U.S. 
In addition, more than half of the participants reported decreased breakfast sizes after immigration. Pan et al. (1999) found that $49 \%$ of the 63 Asian college students identified breakfast as their most commonly skipped meal, which suggests that those who reported decreased breakfast sizes in current study may have actually skipped breakfast. A decrease in breakfast size could be due to a lack of readily accessible Chinese style breakfasts (e.g., unavailability of Chinese street breakfast) or lack of time to prepare the meal because of hectic school schedules. Findings from this study also support this assumption as $73 \%$ of the participants reported a decreased consumption of Chinese style breakfast.

Furthermore, a majority (73\%) of Chinese college students felt that unhealthy food was more accessible in the U.S., and nearly $50 \%$ reported increased unhealthy food affordability compared to that in China. The awareness of the unfavorable food environment could be a buffer that may help students maintain their healthy dietary habits, although students reported both the accessibility and affordability change affected their food choices. The specific roles that immigration-related food environment changes play in dietary acculturation process should be examined further with qualitative studies. With regard to physical activity, almost 50\% of Chinese college students felt that the accessibility of vigorous or moderate physical activity opportunities is higher in the U.S. Nevertheless, whether they became more physically active after immigration is unknown, due to lack of information about physical activity before immigration. Findings of this study indicated a positive correlation between length of U.S. residence and amount of physical activity in male participants. However, this does not necessarily mean a real 
increase in physical activity level after immigration. For example, male students may have experienced a decreased physical activity level during the early period of their immigration, after which they gradually returned to their original physical activity level since becoming more familiar with the availability, accessibility and culture of physical activity in the U.S. The increased time spent in sedentary behaviors reported in this study, as well as the summary of physical activity changes among Asian immigrants from Oakkar et al. (2015) also supports this supposition.

Regarding the reported physical activity changes, students reported decreased time spent bicycling and stair climbing after immigration and increased time spent walking. The decreased bicycling and stair climbing time could be due to the immigration-related changes in bicycling and stair climbing accessibility, such as a lack of knowledge of the U.S. bicycling laws and a higher accessibility of elevators in buildings in the U.S. The increased time spent walking may partly result from fewer bicycling opportunities. While the majority of bicycling in the U.S. is for recreation rather than transportation (Xing, Handy, \& Mokhtarian, 2010), bicycling in China is primarily for transportation purposes. When there is a lack of bicycling or its alternatives (e.g., riding an electric bicycle/a motorcycle) as an efficient method of short-distance transportation, walking could possibly then become a substitute.

Results from the examination of length of residence generally suggest that physical activity acculturation did not differ by length of residence. Similar results were reported in a previous study, in which Corlin et al. (2014) observed no significant differences in amount of physical activity between Chinese immigrants who had resided 
in the U.S. for longer than ten years and more recent immigrants. Another study found that low, moderate and vigorous-intensity physical activity did not differ by length of residence in the U.S. among older Chinese immigrants (Wong et al., 2013). However, in a cross-sectional study of Chinese immigrants in New York City, Afable et al. (2016) found that longer duration of U.S. residence was associated a greater likelihood of leisure-time physical activity (at least $10 \mathrm{~min}$ ), but a lower likelihood of work related physical activity. This variation in findings may be due to the different ways in which physical activity were categorized.

Overall, there were no statistically significant relationships between length of residence in the U.S. and the above discussed acculturation variables (except portion size). One explanation could be that these dietary and physical activity behavior changes occur soon after immigration to the U.S. (Rosenmoller et al., 2011). Liu et al. (2010) also suggested that changes in diet quality could occur early in the acculturation process. Because some health related behaviors may change gradually over time while others may be adopted immediately after immigration, using length of residence as a measure of acculturation to assess the relationship between acculturation and health related behavior changes may not be appropriate under some circumstances.

\section{Length of Residence and Weight Status}

In this study, nearly half participants reported a more than $2.5 \mathrm{~kg}$ weight gain after immigrating to the U.S., while Pan et al. (1999) found that $62 \%$ of the Asian college students reported a gain of about 5 pounds $(2.3 \mathrm{~kg})$ in their weight. In a recent mixed methodology research study, Wu and Smith (2016) also found that a majority of Chinese 
students experienced weight gain. However, in current study, no associations between and length of residence and BMI or WC were observed. Similarly, in their cross-sectional study, Wong et al. (2013) found no associations between length of residence in the U.S. and BMI or WC with their sample of 125 older Chinese individuals. Another study also suggested that duration of time in the U.S. is not associated with BMI among Chinese immigrants (Corlin et al., 2014). In contrast, Yeh et al. (2009) reported that Chinese Americans with length of residence in the U.S. at least 16 years had a significantly higher BMI than those who had lived in the U.S. 5 years or less. A similar result was reported in a cross-sectional study of Chinese immigrants in New York City (Afable et al., 2016). This discrepancy in results could be related to differences in duration of residence of the investigated populations as well as differences in how length of residence was used as a variable (continuous vs. categorical).

Although no associations between longer length of residence and higher BMI or WC were found, a positive correlation between length of residence in the U.S. and BMI change was observed in male participants. A similar result was reported in a previous longitudinal study among Chinese immigrant women in which Tseng et al. (2015) found that longer U.S. residence was associated with an increase in BMI. However, another longitudinal study with Chinese sample aged 45-84 years found no evidence of greater BMI and WC increases over time among foreign-born Chinese (Albrecht et al., 2013). This dissimilarity in outcome could be related to age differences in the study samples. In addition, inconsistent with findings from current study, Oakkar et al. (2015) found that a shorter length of U.S. residence was associated with larger 5-year increases in BMI 
among foreign-born Asian men, with similar trend among Chinese men. This difference in outcome could be related to differences in duration of residence of the investigated populations. A majority of the Chinese college students in the current study had a length of residence of no more than 5 years, while the findings from Oakkar et al. (2015) were based on comparisons between Asians who had lived in the U.S. for longer than 25 years and those with 11-25 years as well as less than 10 years length of residence.

Nevertheless, findings from Oakkar et al. (2015) and current study together suggest that immigrants who recently immigrated are particularly susceptible to increases in BMI. Further studies are needed to investigate this hypothesis.

\section{Dietary/Physical Activity Acculturation and Weight Status}

Previous research suggests that the association between a longer length of residence and higher weight or risk of obesity may be in part due to the adoption of unhealthy behaviors after immigration, such as poor dietary patterns and a sedentary lifestyle (Albrecht et al., 2013).

The results from the current study revealed that adoption of a Western diet was significantly associated with weight gain, which agrees with findings from $\mathrm{Wu}$ and Smith (2016), but may not predispose Chinese immigrants to obesity, which is consistent with the conclusion from Oster and Yung (2010). Like current study, Almohanna, Conforti, Eigel and Barbeau (2015) concluded that there was a gradual shift in the dietary patterns of international students towards a Western diet, and dietary acculturation led to weight gain among some of the students. In addition, results of the current study also indicated that BMI change significantly differ by portion size change. This observation could be 
attributed to the fact that larger portion sizes can lead to significant increases in calorie intake which result in weight gain (Berg \& Forslund, 2015; Ello-Martin, Ledikwe, \& Rolls, 2005).

Besides portion size, meal sizes also changed among Chinese college students after immigration. Traditionally, Chinese culture values eating "Breakfast like a king, lunch like a prince, and dinner like a pauper." However, after immigration, Chinese college students were very likely (55\%) to have decreased breakfast sizes, while same percentage (27\%) of students reported either increased or decreased lunch sizes, and over one third reported increased dinner sizes. The results of this study indicated that BMI change was positively correlated with dinner size change in males. In addition, this study revealed that a decreased lunch size was negatively correlated with BMI change in male students while it was positively correlated with BMI change in female students. In summary, findings of the current study suggest a gender difference in the relationships between BMI change and meal size changes.

For male college students, larger meal sizes (including lunch and dinner) contributed to weight gain possibly through a mechanism similar to that of portion size. On the other hand, a significant negative correlation between lunch size and dinner size was observed among female students. This could probably explain the positive correlation between decreased lunch size and increased BMI change, and suggest that female students shifted their biggest meal from lunch to dinner. Although no significant positive correlation between dinner size and BMI change was observed in female students, it seems that meal size changes could possibly lead to increases in BMI among 
females probably due to a change in distribution of energy intake throughout the day. Results from an earlier study (Hermengildo et al., 2016), which found an association between higher percent energy intake at lunch and a lower risk of weight gain, also support current findings. Berg and Forslund (2015) also suggested that consuming the major part of the energy intake at the end of the day seems to be unfavorable for bodyweight balance. In a previous qualitative study conducted by Weisberg-Shapiro and Devine (2015), their Dominican women participants also attributed their weight gain to the shift of the biggest meal from the middle of the day to night.

Regarding physical activity, no relationship between physical activity acculturation and weight status was found in the current sample. This may partly be due to the physical activity acculturation indicators chosen in this study, and the inaccuracy of self-reported physical activity changes in assessing real physical activity changes. In addition, there is a lack of information about how the overall physical activity level changed since immigration. Future longitudinal studies focusing on the total physical activity level change (i.e., measuring physical activity levels before and after immigration) are needed to assess whether physical activity acculturation affects weight status.

\section{Limitations}

Several limitations should be considered when interpreting findings from this study. As a cross-sectional study, one can neither discern causal relationships, nor examine changes over time (Chen et al., 2012; Tovar et al., 2014). Although participants were asked about changes in diet and physical activity, the self-reported changes may be 
biased, resulting in underestimation of dietary intakes and overestimation of physical activity amounts and intensity. In addition, generalizability of results of this this study is limited, because it included a convenience sample of college students who were young adults with a high level post-secondary education as well as relatively shorter length of U.S. residence. At the same time, students who had concerns with their weight status (being overweight or obese) may less likely to have volunteered to participate if they felt uncomfortable to share their weight information. Thus, compared with the overall Chinese immigrants, this sample was likely to be healthier and less acculturated. Furthermore, generalizability of the results may also be limited due to the small sample size as well as the potential methodological issue. The number of statistical tests may have inflated the type I error rate, and this could possibly be another limitation.

\section{Conclusions}

This study was performed to investigate the associations between length of residence, dietary/physical activity acculturation and weight status. Findings suggested a positive association between Western dietary acculturation and weight gain in Chinese college students.

The examination of length of residence as a continuous variable has implications for future studies on the duration effect - relationships between length of residence and health outcomes. As Ro (2014) pointed out, non-linear duration patterns could be a methodological shortcoming; they further suggested that future research should incorporate a range of alternative coding patterns for length of residence to consider a wider variety of duration patterns. 
The observed associations of acculturation and length of residence with weight status in this study may help elucidate some of the pathways implicated in the process of unhealthy assimilation among immigrants. However, whether length of residence affects weight status through dietary and physical activity acculturation needs further investigations through longitudinal studies. In order to more fully understand the potential influence of variables on weight gain, future longitudinal studies should measure changes in dietary and physical activity patterns in multiple dimensions. This would include more precisely investigating what, when and how much immigrants eat, as well as the types and patterns of physical activity (such as leisure, transportation, or work-related physical activity) before and after immigration.

The variability in findings when examining BMI and BMI change in this study also have implications for work with weight status among immigrant populations. According to Oakkar et al. (2015), BMI examined in a cross-sectional study might have been the same since pre-migration, suggesting that the findings about relationships between length of residence and weight status indicators like BMI and WC were based on an assumption that weight status of immigrants have changed over time. In addition, Goel, McCarthy, Phillips, and Wee (2004) also pointed out that the prevalence of obesity among immigrants who lived in the U.S. for at least 15 years approached that of U.S.born adults. As a result, examining the trajectory of BMI or WC changes among immigrants, especially within immigrant groups having relatively shorter length of residence, may be more applicable when studying health outcomes over time in related to weight status. 
The findings related to dietary and physical activity acculturation among Chinese college students in this study have important implications for interventions. Future interventions should focus on multi-dimensional dietary behavior changes, especially portion size and meal size changes, and consider the importance of physical activity changes that occur as a result of immigration. Such a focus in the early process of acculturation is needed to help maintain healthy weight status and to prevent individuals from becoming overweight or obese for this population. 


\section{References}

Almohanna, A., Conforti, F., Eigel, W., \& Barbeau, W. (2015). Impact of dietary acculturation on the food habits, weight, blood pressure, and fasting blood glucose levels of international college students. Journal of American College Health, 63(5), 307-314.

Albrecht, S.S., Diez Roux, A.V., Kandula, N.R, Osypuk, T.L., Ni, H., \& Shrager, S. (2013). Immigrant assimilation and BMI and waist size: a longitudinal examination among Hispanic and Chinese participants in the multi-ethnic study of atherosclerosis. Obesity (Silver Spring, Md.), 21(8), 1695-703.

Afable, A., Yeh, M., Trivedi, T., Andrews, E., \& Wylie-Rosett, J. (2016). Duration of U.S. residence and obesity risk in NYC Chinese immigrants. Journal of Immigrant and Minority Health, 18(3), 624-635.

Berg, C., \& Forslund, H. (2015). The influence of portion size and timing of meals on weight balance and obesity. Current Obesity Reports, 4(1), 11-18.

Cheung, B.Y., Chudek, M., \& Heine, S.J. (2011). Evidence for a sensitive period for acculturation: younger immigrants report acculturating at a faster rate. Psychological Science, 22(2), 147-52.

Chen, L., Juon, H., \& Lee, S. (2012). Acculturation and BMI among Chinese, Korean and Vietnamese adults. Journal of Community Health, 37(3), 539-546.

Corlin, L., Woodin, M., Thanikachalam, M., Lowe, L., \& Brugge, D. (2014). Evidence for the healthy immigrant effect in older Chinese immigrants: A cross-sectional study. BMC Public Health, 14, 603. 
Oakkar, E.E., Stevens, J., Bradshaw, P.T., Cai, J., Perreira, K.M., Popkin, B.M., GordonLarsen, P., Young, D.R., Ghai, N.R., Caan, B., \& Quinn, V.P. (2015). Longitudinal study of acculturation and BMI change among Asian American men. Preventive Medicine, 73, 15-21.

Ello-Martin, J.A., Ledikwe, J.H., \& Rolls, B.J. (2005). The influence of food portion size and energy density on energy intake: implications for weight management. American Journal of Clinical Nutrition, 82(1), 236S.

General Administration of Sport of China. (2014). National physique monitoring report. Retrieved from: http://www.sport.gov.cn/n16/n1077/n1227/7328132.html

Goel, M.S., McCarthy, E.P., Phillips, R.S., \& Wee, C.C. (2004). Obesity among U.S. immigrant subgroups by duration of residence. JAMA, 292(23), 2860-7.

Hooper, K., \& Batalova, J. (2015, January 28). Chinese immigrants in the United States. Migration Information Source, the online journal of The Migration Policy Institute, Washington, DC. Retrieved from: http://www.migrationpolicy.org/article/chinese$\underline{\text { immigrants-united-states }}$

Hermengildo, Y., López-García, E., García-Esquinas, E., Pérez-Tasigchana, R.F., Rodríguez-Artalejo, F., \& Guallar-Castillón, P. (2016). Distribution of energy intake throughout the day and weight gain: a population-based cohort study in Spain. British Journal of Nutrition, 115(11), 2003-2010.

International Physical Activity Questionnaire. (2004). Guidelines for data processing and analysis of the international physical activity questionnaire (IPAQ) - short form, version 2.0. Retrieved from: https://sites.google.com/site/theipaq/scoring-protocol 
Kandual, N.R., \& Lauderdale, D.S. (2005). Leisure time, non-leisure time, and occupational physical activity in Asian Americans. Annals of Epidemiology, 15(4), $257-265$.

Kwok, S., Mann, L., Wong, K., \& Blum, I. (2009). Dietary habits and health beliefs of Chinese Canadians. Canadian Journal of Dietetic Practice and Research: A Publication of Dietitians of Canada, 70(2), 73-80.

Lê-Scherban, F., Albrecht, S.S., Osypuk, T.L., Sánchez, B.N., \& Diez Roux, A.V. (2014). Neighborhood ethnic composition, spatial assimilation, and change in body mass index over time among Hispanic and Chinese immigrants: multi-ethnic study of atherosclerosis. American Journal of Public Health, 104(11), 2138-46.

Liu, A., Berhane, Z., \& Tseng, M. (2010). Improved dietary variety and adequacy but lower dietary moderation with acculturation in Chinese women in the United States. Journal of the American Dietetic Association, 110(3), 457-462.

Lv, N., \& Cason, K.L. (2004). Dietary pattern change and acculturation of Chinese Americans in Pennsylvania. Journal of the American Dietetic Association, 104(5), $771-778$.

Lee, M.M., Wu-Williams, A., Whittemore, A.S., Zheng, S., Gallagher, R., Teh, C.Z., Zhou, L., Wang, X., Chen, K., \& Ling, C. (1994). Comparison of dietary habits, physical activity and body size among Chinese in North America and China. International Journal of Epidemiology, 23(5), 984-90. 
Monda, K.L., Adair, L.S., Zhai, F., \& Popkin, B.M. (2008). Longitudinal relationships between occupational and domestic physical activity patterns and body weight in China. European Journal of Clinical Nutrition, 62(11), 1318.

Oster, A., \& Yung, J. (2010). Dietary acculturation, obesity, and diabetes among Chinese immigrants in New York City. Diabetes Care, 33(8), E109.

Pan, Y., Dixon, Z., Himburg, S., \& Huffman, F. (1999). Asian students change their eating patterns after living in the United States. Journal of the American Dietetic Association, 99(1), 54.

Ro, A. (2014). The longer you stay, the worse your health? a critical review of the negative acculturation theory among Asian immigrants. International Journal of Environmental Research and Public Health, 11(8), 8038-8057.

Rosenmoller, D.L., Gasevic, D., Seidell, J., \& Lear, S.A. (2011). Determinants of changes in dietary patterns among Chinese immigrants: a cross-sectional analysis. International Journal of Behavioral Nutrition and Physical Activity, 8(1), 42-49.

Satia, J.A., Patterson, R.E., Kristal, A.R, Hislop, T.G., Yasui, Y., \& Taylor, V.M. (2001). Development of scales to measure dietary acculturation among Chinese-Americans and Chinese-Canadians. Journal of the American Dietetic Association, 101(5), 548553.

Spindler, A., \& Schultz, J. (1996). Comparison of dietary variety and ethnic food consumption among Chinese, Chinese-American, and white American women. Agriculture and Human Values, 13(3), 64-73. 
Sun, W.Y., \& Wu, J.S. (1997). Comparison of dietary self-efficacy and behavior among American-born and foreign-born Chinese adolescents residing in New York City and Chinese adolescents in Guangzhou, China. Journal of the American College of Nutrition, 16(2), 127-133.

Tovar, A., Boulos, R., Sliwa, S., Must, A., Gute, D., Metayer, M. \& Economos, A. (2014). Baseline socio-demographic characteristics and self-reported diet and physical activity shifts among recent immigrants participating in the randomized controlled lifestyle intervention: "live well". Journal of Immigrant and Minority Health, 16(3), 457-465.

Tseng, M., Wright, D., \& Fang, J. (2015). Acculturation and dietary change among Chinese immigrant women in the United States. Journal of Immigrant and Minority Health, 17(2), 400-407.

Taylor, V.M., Yasui, Y., Tu, S.P., Neuhouser, M.L., Li, L., Woodall, E., Acorda, E., Cripe, S.M., \& Hislop, T.G. (2007). Heart disease prevention among Chinese immigrants. Journal of Community Health, 32(5), 299-310.

Unger, J., Reynolds, B., Shakib, K., Spruijt-Metz, S., Sun, D., \& Johnson, P. (2004). Acculturation, physical activity, and fast-food consumption among Asian-American and Hispanic adolescents. Journal of Community Health, 29(6), 467-481.

Weisberg-Shapiro, P., \& Devine, C.M. (2015). "Because we missed the way that we eat at the middle of the day:" dietary acculturation and food routines among Dominican women. Appetite, 95, 293. 
Wong, S.S., Dixon, L.B., Gilbride, J.A., Kwan, T.W., \& Stein, R.A. (2013). Measures of acculturation are associated with cardiovascular disease risk factors, dietary intakes, and physical activity in older Chinese Americans in New York City. Journal of Immigrant and Minority Health, 15(3), 560-568.

World Health Organization. (2015). Global database on body mass index. Retrieved from: http://apps.who.int/bmi/index.jsp?introPage=intro_3.html

Wu, B., \& Smith, C. (2016). Acculturation and environmental factors influencing dietary behaviors and body mass index of Chinese students in the United States. Appetite, $103,324-335$.

Xing, Y., Handy, S.L., \& Mokhtarian, P.L. (2010). Factors associated with proportions and miles of bicycling for transportation and recreation in six small U.S. cities. Transportation Research Part D, 15(2), 73-81.

Yan, Z., \& Cardinal, B.J. (2013). Perception of physical activity participation of Chinese female graduate students: a case study. Research Quarterly for Exercise and Sport, 84(3), 384-396.

Yeh, M., Fahs, M., Shelley, D., Yerneni, R., Parikh, N.S., \& Burton, D. (2009). Body weight and length of residence in the U.S. among Chinese Americans. Journal of Immigrant and Minority Health, 11(5), 422-427. 


\section{Appendix A. Dietary and Physical Activity Acculturation Survey}

\section{Subject \#}

\section{Socio-demographic Information}

1. Age

2. Gender: $\square$ male $\square$ female

3. Are you currently pregnant? $\square$ Yes $\square$ No $\square$ not apply

4. The length of residence in the U.S. months

5. Education level: $\square$ undergraduate $\square$ graduate $\square$ other

6. Marital status: $\square$ married $\square$ unmarried

7. Smoking status: $\square$ current smoker $\square$ former smoker $\square$ non-smoker

8. Self-identity: $\square$ Chinese $\square$ American $\square$ equal $\square$ other

\section{Dietary Acculturation Scales}

\begin{tabular}{|l|c|c|c|c|c|}
\hline $\begin{array}{l}\text { Scale item } \\
\text { “After came to America, you ...” }\end{array}$ & $\begin{array}{c}\text { Much } \\
\text { less }\end{array}$ & $\begin{array}{c}\text { No } \\
\text { change }\end{array}$ & $\begin{array}{c}\text { Much } \\
\text { More }\end{array}$ \\
\hline Chinese items & 1 & 2 & 3 & 4 & 5 \\
\hline Eat tofu & & & & & \\
\hline Eat on time & & & & & \\
\hline Eat a Chinese-style breakfast & & & & & \\
\hline Balance yin/yang foods & & & & & \\
\hline Eat traditionally preserved foods & & & & & \\
\hline Avoid cold foods and drinks & & & & & \\
\hline Western items & & & & & \\
\hline Eat bread, rolls, or bagels & & & & & \\
\hline Eat sweets, cakes, or pies for dessert & & & & & \\
\hline Drink milk products & & & & & \\
\hline Eat between meals & & & & & \\
\hline Eat at Western fast-food restaurants & & & & & \\
\hline Eat pizza or spaghetti with tomato sauce & & & & & \\
\hline Eat ground beef and hamburgers & & & & & \\
\hline Eat packaged or prepared foods, e.g., TV dinners & & & & & \\
\hline Drink carbonated beverages & & & & & \\
\hline Eat any kind of cheese & & & & & \\
\hline
\end{tabular}




\section{International Physical Activity Questionnaire}

Think about all the vigorous activities that you did in the last $\mathbf{7}$ days. Vigorous physical activities refer to activities that take hard physical effort and make you breathe much harder than normal. Think only about those physical activities that you did for at least 10 minutes at a time.

1. During the last $\mathbf{7}$ days, on how many days did you do vigorous physical activities like heavy lifting, digging, aerobics, or fast bicycling?

days per week

$\square$ No vigorous physical activities $\longrightarrow$ Skip to question 3

2. How much time did you usually spend doing vigorous physical activities on one of those days? hours per day _ _ minutes per day $\square$ Don't know/Not sure

Think about all the moderate activities that you did in the last $\mathbf{7}$ days. Moderate activities refer to activities that take moderate physical effort and make you breathe somewhat harder than normal. Think only about those physical activities that you did for at least 10 minutes at a time.

3. During the last $\mathbf{7}$ days, on how many days did you do moderate physical activities like carrying light loads, bicycling at a regular pace, or doubles tennis? Do not include walking.

days per week

$\square$ No moderate physical activities $\longrightarrow$ Skip to question 5

4. How much time did you usually spend doing moderate physical activities on one of those days?

hours per day minutes per day $\square$ Don't know/Not sure

Think about the time you spent walking in the last $\mathbf{7}$ days. This includes at work and at home, walking to travel from place to place, and any other walking that you might do solely for recreation, sport, exercise, or leisure.

5. During the last $\mathbf{7}$ days, on how many days did you walk for at least 10 minutes at a time?

days per week

$\square$ No walking $\longrightarrow$ Skip to question 7

6. How much time did you usually spend walking on one of those days?

hours per day

minutes per day $\square$ Don't know/Not sure

The last question is about the time you spent sitting on weekdays during the last $\mathbf{7}$ days. Include time spent at work, at home, while doing course work and during leisure time. This may include time spent sitting at a desk, visiting friends, reading, or sitting or lying down to watch television.

7. During the last $\mathbf{7}$ days, how much time did you spend sitting on a week day? hours per day minutes per day

$\square$ Don't know/Not sure 


\section{Self-Reported Changes in Diet, Physical Activity and Weight Status Questions}

\begin{tabular}{|c|c|c|}
\hline Questions & Sub-items & Answer possibilities \\
\hline $\begin{array}{l}\text { How have your general } \\
\text { eating habits changed } \\
\text { since coming to America? }\end{array}$ & 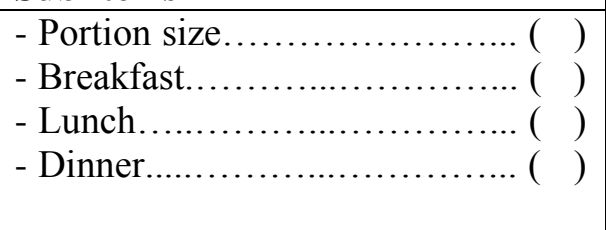 & $\begin{array}{l}\text { 1. Eat much less } \\
\text { 2. } \\
\text { 3. No Change } \\
\text { 4. } \\
\text { 5. Eat much more }\end{array}$ \\
\hline $\begin{array}{l}\text { How do you feel about the } \\
\text { accessibility/affordability } \\
\text { in America compared to } \\
\text { your home country? }\end{array}$ & $\begin{array}{l}\text { - Healthy food accessibility...... ( ) } \\
\text { - Unhealthy food accessibility... ( ) } \\
\text { - Healthy food affordability..... ( ) } \\
\text { - Unhealthy food affordability... ( ) }\end{array}$ & $\begin{array}{l}\text { 1. Much lower here } \\
\text { 2. } \\
\text { 3. No change } \\
\text { 4. } \\
\text { 5. Much higher here }\end{array}$ \\
\hline $\begin{array}{l}\text { How likely do you feel } \\
\text { that these changes have } \\
\text { affected your food choice? }\end{array}$ & $\begin{array}{l}\text { - Healthy food accessibility....... ( ) } \\
\text { - Unhealthy food accessibility.... ( ) } \\
\text { - Healthy food affordability....... ( ) } \\
\text { - Unhealthy food affordability.... ( ) }\end{array}$ & $\begin{array}{l}\text { 1. Not at all } \\
2 . \\
3 . \\
\text { 4. } \\
\text { 5. Very likely }\end{array}$ \\
\hline $\begin{array}{l}\text { How do you feel about } \\
\text { these accessibilities in } \\
\text { America compared to } \\
\text { your home country? }\end{array}$ & $\begin{array}{l}\text { - Vigorous physical activity...... ( ) } \\
\text { - Moderate physical activity...... ( ) }\end{array}$ & $\begin{array}{l}\text { 1. Much lower here } \\
\text { 2. } \\
\text { 3. No change } \\
\text { 4. } \\
\text { 5. Much higher here }\end{array}$ \\
\hline $\begin{array}{l}\text { How has your time spent } \\
\text { on these activities } \\
\text { changed since coming to } \\
\text { America? }\end{array}$ & $\begin{array}{l}\text { - Walking........................... ( }) \\
\text { - Running............................ ( ) } \\
\text { - Bicycling..................... ( }) \\
\text { - Walking up stairs................. ( ) } \\
\text { - Sedentary behaviors............ }\end{array}$ & $\begin{array}{l}\text { 1. Much less } \\
\text { 2. } \\
\text { 3. No change } \\
\text { 4. } \\
\text { 5. Much more }\end{array}$ \\
\hline $\begin{array}{l}\text { How likely do you feel } \\
\text { that the change of physical } \\
\text { activity accessibility has } \\
\text { affected your time spent } \\
\text { on these activities? }\end{array}$ & $\begin{array}{l}\text { - Walking........................... ( ) } \\
\text { - Running........................... ( }) \\
\text { - Bicycling...................... ( }) \\
\text { - Walking up stairs............... }\end{array}$ & $\begin{array}{l}\text { 1. Not at all } \\
2 . \\
3 . \\
\text { 4. } \\
\text { 5. Very likely }\end{array}$ \\
\hline $\begin{array}{l}\text { How likely do you feel } \\
\text { that your behavior changes } \\
\text { have affected your weight } \\
\text { status? }\end{array}$ & $\begin{array}{l}\text { - Dietary behavior................... ( ) } \\
\text { - Physical activity............. ( ) }\end{array}$ & $\begin{array}{l}\text { 1. Not at all } \\
2 . \\
3 . \\
\text { 4. } \\
\text { 5. Very likely }\end{array}$ \\
\hline $\begin{array}{l}\text { How has your weight } \\
\text { changed since coming to } \\
\text { America? }\end{array}$ & $\begin{array}{ll}\ldots & \text { pound }(\mathrm{s}) \\
\text { or } & \\
& \text { kilogram }(\mathrm{s})\end{array}$ & $\begin{array}{l}\square \text { Weight gain } \\
\square \text { Weight loss } \\
\square \text { No change } \\
\square \text { Not sure }\end{array}$ \\
\hline
\end{tabular}

\section{This is the end of the questionnaire, thank you for participating.}




\title{
Appendix B. Human Subjects Approval
}

\author{
The Portland State University \\ Consent to Participate in Research \\ Dietary and Physical Activity Acculturation and Weight Status in Chinese College \\ Students
}

02.18 .2016

\section{Introduction}

You are being asked to participate in a research study conducted by Yanni Zhang, who is the Principal Investigator, from the School of Community Health, at Portland State University in Portland, Oregon. This research is studying (1) the relationships between dietary acculturation, physical activity acculturation and the length of residence in the U.S. among Chinese college students; and (2) the relationships between dietary acculturation, physical activity acculturation and weight status among Chinese college students.

You are being asked to participate in this study because you have been identified as a Chinese college student at PSU.

This form explains the research study, and also explains the possible risks and possible benefits to you. We encourage you to talk with your family and friends before you decide to take part in this research study. If you have any questions, please ask one of the study investigators.

\section{What will happen if I decide to participate?}

If you agree to participate, the following things will happen:

Your height, weight, and waist circumference will be measured first. Then you will complete a Diet and Physical Activity (PA) Survey including: (1) basic sociodemographic information; (2) a diet acculturation questionnaire; (3) the International Physical Activity Questionnaire; and (4) a self-reported changes in diet, physical activity and weight status questionnaire.

\section{How long will I be in this study?}

Participation in this study will take a total of 0.75 hour ( 45 minutes) over a period of one day. 


\section{What are the risks or side effects of being in this study?}

There are small risks of stress, emotional distress, inconvenience and possible loss of privacy and confidentiality associated with participating in this research study.

When recalling the dietary or physical activity behavior changes, there is a small chance that you may feel emotional discomfort/distress if you feel homesick or feel reminded of possible unhealthy lifestyle behaviors. PSU SHAC counseling services will be available to you at no cost if you experience any distress. If you prefer a private space to complete the survey alone, the student investigator will leave the room after she explains any questions you may have with the Survey.

For more information about risks and discomforts, ask the investigator.

\section{What are the benefits to being in this study?}

You may gain the benefit by knowing you have added to the body of knowledge pertaining to acculturation and weight status. You may also benefit by learning about your individual diet and physical activity acculturation (as well as your own weight status) after the thesis has been defended. You can provide the principal investigator with your subject number and e-mail for a copy of the results of the study.

\section{How will my information be kept confidential?}

We will take measures to protect the security of all your personal information, but we cannot guarantee confidentiality of all study data. Every effort will be made to uphold confidentiality of your identity and collected data. Once admitted into the study, you will be assigned a subject number. All data will be coded under this number so that the research team will be unaware of your true identity. All original documentation will be stored in a sealed envelope in a locked file cabinet. Your individual results will remain confidential and unavailable to the general public.

Information contained in your study records is used by study staff. The Portland State University Institutional Review Board (IRB) that oversees human subject research and/or other entities may be permitted to access your records, and there may be times when we are required by law to share your information. It is the investigator's legal obligation to report child abuse, child neglect, elder abuse, harm to self or others or any lifethreatening situation to the appropriate authorities; therefore, your confidentiality will not be maintained.

Your name will not be used in any published reports about this study. 


\section{Will I be paid for taking part in this study?}

No, but you are eligible for a drawing of five \$10 gift cards after all data are collected; you can refuse to be included in the drawing if you wish.

\section{Can I stop being in the study once I begin?}

Your participation in this study is completely voluntary. You have the right to choose not to participate or to withdraw your participation at any point in this study without penalty or loss of benefits to which you are otherwise entitled.

\section{Whom can I call with questions or complaints about this study?}

If you have any questions, concerns or complaints at any time about the research study, Yanni Zhang, or her associates will be glad to answer them at 971-300-2802.

If you need to contact someone after business hours or on weekends, please call 971-3002802 and ask for Yanni Zhang.

\section{Whom can I call with questions about my rights as a research participant?}

If you have questions regarding your rights as a research participant, you may call the PSU Office for Research Integrity at (503) 725-2227 or 1(877) 480-4400 (or 1600 S.W. $4^{\text {th }}$ Avenue, Market Center Building, Suite 620, Portland, OR 97201). The ORI is the office that supports the PSU Institutional Review Board (IRB). The IRB is a group of people from PSU and the community who provide independent oversight of safety and ethical issues related to research involving human participants. For more information, you may also access the IRB website at https://sites.google.com/a/pdx.edu/research/integrity.

\section{CONSENT}

You are making a decision whether to participate in this study. Your signature below indicates that you have read the information provided (or the information was read to you). By signing this consent form, you are not waiving any of your legal rights as a research participant.

You have had an opportunity to ask questions and all questions have been answered to your satisfaction. By signing this consent form, you agree to participate in this study. A copy of this consent form will be provided to you. 
Name of Adult Subject (print) Signature of Adult Subject Date

\section{INVESTIGATOR SIGNATURE}

This research study has been explained to the participant and all of his/her questions have been answered. The participant understands the information described in this consent form and freely consents to participate.

$\overline{\text { Name of Investigator/ Research Team Member (type or print) }}$

(Signature of Investigator/ Research Team Member) Date 